WellBeing International

WBI Studies Repository

$5-2016$

\title{
An Ethogram for Benthic Octopods (Cephalopoda: Octopodidae)
}

Jennifer Mather

University of Lethbridge

Jean S. Alupay

University of Southern California

Follow this and additional works at: https://www.wellbeingintlstudiesrepository.org/physio

Part of the Animal Studies Commons, Other Animal Sciences Commons, and the Veterinary

Physiology Commons

\section{Recommended Citation}

Mather, J. A., \& Alupay, J. S. (2016, April 14). An Ethogram for Benthic Octopods (Cephalopoda: Octopodidae). Journal of Comparative Psychology. Advance online publication. http://dx.doi.org/ $10.1037 /$ com0000025

This material is brought to you for free and open access by WellBeing International. It has been accepted for inclusion by an authorized administrator of the WBI Studies Repository. For more information, please contact wbisr-info@wellbeingintl.org.

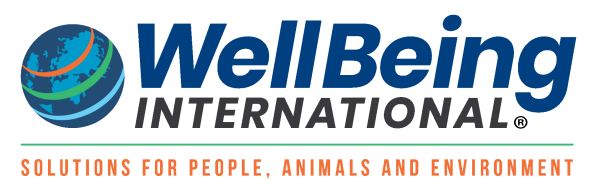




\title{
An Ethogram for Benthic Octopods (Cephalopoda: Octopodidae)
}

Jennifer A. Mather ${ }^{1}$ and Jean S. Alupay ${ }^{2}$

1 University of Lethbridge

2 University of Southern California

\section{KEYWORDS}

muscular hydrostat, octopus, skin displays

\begin{abstract}
The present paper constructs a general ethogram for the actions of the flexible body as well as the skin displays of octopuses in the family Octopodidae. The actions of 6 sets of structures (mantle-funnel, arms, sucker-stalk, skin-web, head, and mouth) combine to produce behavioral units that involve positioning of parts leading to postures such as the flamboyant, movements of parts of the animal with relation to itself including head bob and grooming, and movements of the whole animal by both jetting in the water and crawling along the substrate. Muscular actions result in 4 key changes in skin display: (a) chromatophore expansion, (b) chromatophore contraction resulting in appearance of reflective colors such as iridophores and leucophores, (c) erection of papillae on the skin, and (d) overall postures of arms and mantle controlled by actions of the octopus muscular hydrostat. They produce appearances, including excellent camouflage, moving passing cloud and iridescent blue rings, with only a few known species-specific male visual sexual displays. Commonalities across the family suggest that, despite having flexible muscular hydrostat movement systems producing several behavioral units, simplicity of production may underlie the complexity of movement and appearance. This systematic framework allows researchers to take the next step in modeling how such diversity can be a combination of just a few variables.
\end{abstract}

An ethogram, which can be described as "an inventory of the behavior of a species" (Drickamer, Vessey, \& Meikle, 1996, p. 17), is important as a foundation for behavioral investigation. In a comprehensive ethogram, researchers emphasize the natural behavior of animals within their environment, requiring years of systematic field observation (in the ocean for 
cephalopods) and resulting in an extensive descriptive inventory of behavioral patterns and repertoires (see Greenberg, 1977; Jensen, 1980; Ruby \& Niblick, 1994). This aligns with Andrews' (2015, p.45) recent definition of an ethogram as "the scientific study of the behavior of animals as evolved organisms, in the context of anatomy, physiology and the natural environment." Some of the first cephalopod ethograms described the wide repertoire of body patterning in Octopus vulgaris (Mather \& Mather, 1994; Packard \& Sanders, 1971). More recently, Huffard (2007a) has a list of behaviors for the octopus Abdopus aculeatus. Early ethologists, such as founding fathers Lorenz and Tinbergen, believed that animals' behavior was relatively stereotyped and species-specific, and could be described in an inventory of Fixed Action Patterns (Saraiva, 2006). Such behaviors might be seen as taxonomic characters for octopuses (Hanlon, 1988), although these animals are very dependent on learning (Wells, 1978). Researchers have begun to loosen this definition of standardized behaviors and talk instead of Species- Typical Behaviors or Modal Action Patterns, which are usually seen in most members of a species, possibly only in one sex (Barlow, 1968). These categories might be wider than for a single species and similar across members of a larger taxon, and can also be seen as adaptations to specific environments.

The goal of this paper is to summarize this information to better describe octopus movements and appearances as hierarchical systems with similarities and differences across the family. The present assessment focuses on the better described species of octopuses of the more than 300 (Norman, Finn, \& Hochberg, 2014) in the family Octopodidae and takes a broad view of their actions because of two problems. A first one is that we have fragmentary information yet need to generalize across species. A broad view therefore allows for comparison of specific behaviors from each species to determine overall patterns and generalities, as seen in other groups of animals (e.g., Stenus beetles by Betz, 1999; monkeys by Petrù, Spinka, Charvátová, \& Lhota, 2009). This is the case for members of the family Octopodidae, where information can be gleaned piece by piece from different octopus species. The cross-species account in this ethogram describes 17 species. It draws from pioneering observations on Octopus vulgaris (Altman, 1966; Packard \& Sanders, 1971), but also Octopus joubini (Mather, 1984; Hanlon, 1983), Octopus rubescens (Packard \& Hochberg, 1977; Warren, Scheier, \& Riley, 1974), Octopus briareus (Hanlon \& Wolterding, 1989), Octopus cyanea (Hanlon, Forsythe, \& Joneschild, 1999), and Octopus bimaculoides (Forsythe \& Hanlon, 1988), as well as Eledone cirrhosa (Boyle \& Dubas, 1981) and Enteroctopus (formerly Octopus) dofleini (anecdotal accounts from Cosgrove \& McDaniel, 2009; Packard \& Hochberg, 1977). It includes observations of more recently identified species (Huffard, Saarmann, Hamilton, \& Simison, 2010) such as Wunderpus photogenicus (Hochberg, Norman, \& Finn, 2006), Thaumoctopus mimicus (Hanlon, Conroy, \& Forsythe, 2008), the more social Abdopus aculeatus (Huffard, 2006, 2007a), and the 'Larger Pacific Striped Octopus' (Caldwell, Ross, Rodaniche, \& Huffard, 2015) with pictures and short accounts of individuals of other members of the family like the recently identified Octopus gorgonus (Huffard, 2007b) and Amphioctopus marginatus (Huffard \& Godfrey-Smith, 2010; Sreeja \& Bijukumar, 2013). Although by and large most observations have been made on adult octopuses, there are some known behaviors, particularly in feeding and locomotion, in the earlier planktonic life stages of O. vulgaris (Villanueva, 1995; Villanueva, Nozais, \& Boletzky, 1997), Enteroctopus megalocyathus (Ortiz, Re, \& Marquez, 2006), Octopus maya (Moguel et al., 2010), and newly settled O. cyanea (Wells \& Wells, 1970). The behavior of these species and their skin 
patterns are often more similar than they are distinct, especially with recent changes in taxonomic organization.

A second problem in describing the behavioral units of octopuses is their muscular control systems. The body movement of octopuses, and all Coleoid cephalopod molluscs, is based on muscular hydrostats. These movement systems have no fixed endo-or exoskeleton (Kier \& Thompson, 2003; Yekutieli, Flash, \& Hochner, 2009). Movement of muscular hydrostats is based on the allocation of some muscles as skeleton and others to contraction during an action (Smith \& Kier, 1989). The volume of a muscular hydrostat unit remains constant as the shape changes, and the octopus is a set of these muscle units, generally acting together. In theory, this means that there is an infinite or at least a very large number of degrees of freedom of motion (Gutfreund et al., 1996), making it challenging to delineate typical actions. Research has shown how these degrees of freedom are actually limited, and described the rules of activation that result in a simplification of this complexity (Gutfreund, Flash, Fiorito, \& Hochner, 1998). The control of some of these muscle units has been characterized (Kier \& Smith, 2002; Kier \& Stella, 2007; Uyeno \& Kier, 2007). Specifically, some progress has been made in evaluating how peripheral neural programs control the bending of an octopus arm at typical locations (Sumbre, Gutfreund, Fiorito, Flash, \& Hochner, 2001; Zelman et al., 2013). Even more recently, chemical signals in the skin have been implicated as an explanation for arm self-identity when an octopus is coordinating multiple arm movements (Nesher, Levy, Grasso, \& Hochner, 2014).

From a behavioral point of view, characteristic actions and postures of octopus arms were described by Mather (1998), but a lot of variation between and within species makes describing 'typical' octopus action sequences difficult. Mather's (1986) description of sand digging in Sepia, with predictable transitions between funnel positions when blowing sand, is one good example of a stereotyped sequence of actions. Rather than focus on fixity versus variation, modern approaches have evaluated behavioral rules and sources of variability. Over several decades, researchers focused on neural pattern generators and the resulting rhythmic movement output (Pearson, 1993), in invertebrate and vertebrate animals. Pellis, Pellis, and Iwaniuk (2014) instead emphasized that we must examine the combination of neural rules, environmental input resulting in end-point perceptual results, and the physical constraints of the animal's body, which underlie Hochner's (2013) Embodied Organization approach. For an animal such as the octopus with a muscular hydrostat movement system that can use many degrees of freedom (Kier \& Thompson, 2003), such physical constraints may be less important. Neural organization and routines of motor learning may result in the biases that we see as fixed patterns, and what seem to be complex routines may end up resulting in simple sensory end points (Pellis et al., 2014).

Cephalopods also have a visual appearance system based on elastic pigment-containing elements in the skin called chromatophores, pulled to expansion by muscles (Messenger, 2001; Packard \& Hochberg, 1977). Appearance is assisted by reflective cells (iridophores and leucophores) below the chromatophore layer as well as muscle elements in the skin that form textural units called papillae (Packard \& Hochberg, 1977; see Allen, Bell, Kuzirian, \& Hanlon, 2013, for anatomy of the papillary system in cuttlefish). Appearance is organized spatially, as elements group to make units and small units combine into larger components, adding flexibility in patterning (Packard \& Hochberg, 1977; Packard \& Sanders, 1971). Such a hierarchical system 
was thoroughly described for the appearance of the cuttlefish Sepia officinalis (Hanlon \& Messenger, 1988), and the components evaluated by cluster analysis (Crook, Baddeley, \& Osorio, 2002). The first display repertoires in octopus were done for O. vulgaris (there was a shorter description by Cowdry, 1911 (but see species identification); Mather \& Mather, 1994; most comprehensive by Packard \& Sanders, 1971). Forsythe and Hanlon (1988) created a display repertoire for $O$. bimaculoides, Huffard (2007a) for A. aculeatus and Caldwell et al. (2015) for the Larger Pacific Striped Octopus. Leite and Mather (2008) generated a cluster analysis for components of patterns of $O$. insularis, one of the few quantitative studies of component combinations in octopuses. Comparative accounts of Australian cephalopod display patterns were made by Roper and Hochberg (1988) and those for Caribbean octopuses by Hanlon (1988). Behavior of many groups of cephalopods is summarized in Hanlon and Messenger (1996). Borrelli, Gherardi, and Fiorito (2006) compiled a catalogue for cephalopod body patterning, composed entirely of drawings that illustrate each component. Though useful, they do not provide necessary context for the display that photos from the field can provide. They also clarify redundant terminology that is used, but only for a few well-known cephalopod species. Thus new species' descriptions should be added to any catalogue, particularly of octopus species that have patterns that have not been mentioned (i.e., semipermanent patterns of W. photogenicus, Huffard et al., 2008). These and casual observations of octopuses over the years in the lab and field provide a foundation for a systematic though still incomplete overview.

\section{Motion of Part or All of the Body Systems}

All the behavioral units to be described are actions of one set of structures. Behaviors cannot be described separately from the structural units, so these are given first. Each behavioral unit is a combination of contractions of a major muscle group (sensu Hanlon \& Messenger, 1996), likely based on a physically discrete set of muscle fiber elements. Each can occur by itself and yet is usually seen in combination with other units.

Coleoid cephalopods have a different body arrangement from vertebrates, which must be understood as a basis for these movements (see Figures la and 1b). Their main body areas are the eight anterior Arms, the central Head with mouth apparatus (and thus the name cephalopod, or head-foot), the posterior Mantle and its internal organs, and the Skin (which includes the web). To describe an ethogram of body movements and postures, a default position needs to be defined from which different patterns deviate (see description of 'Standard' in Sepioteuthis sepiodea by Mather, Griebel \& Byrne, 2010). The typical orientation of cephalopods, best exemplified by the elongate and neutrally buoyant body of squid and cuttlefish, is described with the tip of the mantle posterior, the tips of arms anterior, the head-eye region dorsal, and the funnel ventral (see Hanlon \& Messenger, 1996, Figure 2.1). A similar position is seen in octopuses (Figure 1a), which we define here as the Standard position. More specifically, the structural units of an octopus in Standard position can be described as the following: the mantle loosely held horizontal, half expanded with the lateral slits between the body and mantle open; the funnel held loosely open, pointed to the anterior; the arms loosely extended to the anterior, parallel and close to one another with the suckers and their stalks held linearly away from the arms facing orally; and the head slightly risen from the arm-base region (Figure 1a). This is not considered their resting position, as benthic octopuses do not maintain a 
neutral buoyancy, but move along the sea floor relying more on arms for locomotion (Wells \& O'Dor, 1991). Rather, it is a position from which to start evaluation of actions and postures. Octopuses are bilaterally symmetrical, but the eight arms are arranged in a radial array around the mouth, with arms conventionally numbered from mid-dorsal with reference to the head, Left 1-2-3-4 and Right 1-2-3-4 (Figure 1b). They are equipotential in behavior (Mather, 1998) but are specialized in an anterior-posterior direction with the anterior arms used more in exploration (Byrne, Kuba, Meisel, Griebel, \& Mather, 2006) and the posterior ones in walking, but with no discernible gait (Huffard et al., 2005; Levy, Flash, \& Hochner, 2015).

Figure 1. Octopus body plan in (a) lateral Standard position and (b) dorsal view of arm positions, showing anatomical terminology of Robson (1929).

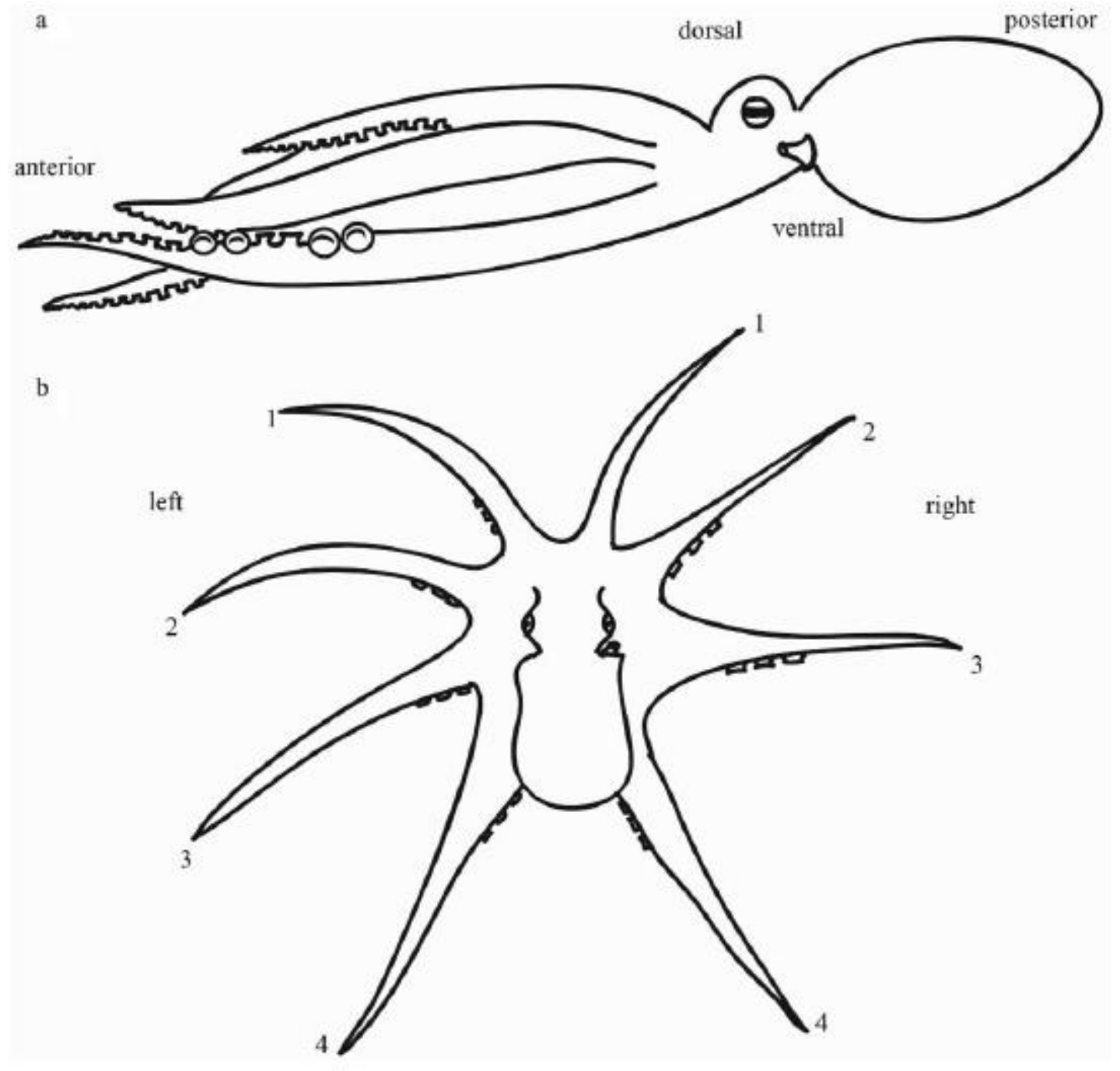

\section{Structural Units}

Mantle-Funnel. The possession of a mantle is a fundamental attribute of molluscs, although the mantle of most members of the phylum secretes a protective shell enclosing an internal 
mantle cavity (Solem, 1974). Without this enclosure, the cephalopod mantle expands and contracts, primarily for ventilation and secondarily for jet propulsion (Alexander, 2003), and can deflate, inflate, or hold (Mather, 1998). Exactly which combination of muscles and what shape differences are found in different amounts of expansion are not yet thoroughly studied in octopuses, although there is some information from the other groups of cephalopods (Kier \& Thompson, 2003). The amount and timing of volume change can be finely graded in ventilation (Boyle, 1976). The funnel can deflect to send jets of water laterally, ventrally, and also dorsally. The tip of the funnel can also fold, closing off the flow of water from inside the mantle, or unfold. The mantle contains slits on both sides that can open and close (Mather, 1998). Closed mantle slits, with inner ridges serving as a bracing point, make it possible for water ejection to be solely through the funnel. Robson (1929, p. 9) refers to these mantle slits as the "pallial aperture, a transverse slit from which the funnel projects." The mantle sometimes holds with a large amount of water inside, but also with less in the ogive posture-partly inflated, especially ventrally, appearing elongated with a pronounced posterior mantle tip (Packard \& Sanders, 1971). The mantle can be held at any angle with relation to the substrate, from up, horizontal, to down.

Arms. Because of the long extension of each arm (over $2 \mathrm{~m}$ in adult $E$. dofleini), it can be described as having proximal, middle, and distal sections along its length. Suckers are specified as facing orally with respect to the arm, and arms are not always of equal length. In Standard position (Figure 1a), arms are appressed, close to one another, along the body midline axis and relaxed, partly extended. The arms can move from this midline all together in different angular amounts of splay, which, when accompanied by arm bending, moves the arms from anterior to posterior along the body midline axis (Mather, 1998). Along its own linear axis, each arm can bend, changing the angle of one part of the arm with reference to others at one location or gradually along an arm segment. Arms can also extend and contract along this axis with relation to their attachment at the proximal end near the head (Mather, 1998). They can twist, rotating around this same arm axis (Kier \& Smith, 1985), anywhere along the arm length but often distally (see Flamboyant posture).

Sucker-Stalk combinations. Each of the hundreds of sucker-stalks can act as a unit, but there are many possibilities for coordination as well. The stalk, which connects the sucker cup to the arm, can move the cup to and move it away from the arm. The stalk can also turn on its linear axis (Mather, 1998). The sucker can grasp, release, and hold (see supplementary video one of $O$. rubescens using all three actions), also perform a pincer grasp (Kier \& Smith, 1990), when the lateral sides of the sucker cup fold toward one another and make a linear grasping surface. One sucker-stalk combination can move as a behavioral unit by itself, as each is controlled by a sucker ganglion (Rowell, 1963, 1966). A group of suckers on one or several arms will normally act together, performing different or similar actions (Grasso, 2014).The morphology and adhesion of suckers have been explored for a variety of octopus species by Kier and Smith (2002) and more recently by Tramacere et al. (2013) in O. vulgaris. More specifically, Tramacere, Appel, Mazzolai, and Gorb (2014) discovered microscopic hairs on the surface of suckers that they speculate plays an added role in adhesion.

Skin/Web. Any part of the animal's surface can be smooth or rugose, depending on the extent to which it has papillae raised or not (Cowdry, 1911; Mather \& Mather, 1994). A special area of the skin, the Web, extends between the arms and can flare and retract (Mather, 1998). 
There are eight web areas, one between each pair of arms, and they can be positioned separately. Webs can flare from the arm bases (O. vulgaris) or laterally from one or more arms (O. cyanea). They can move symmetrically in displays (e.g., Dymantic) but often they do not, when the web is used to assist in prey capture (e.g., Webover).

Head. It is considered the physical center of the body. Between the arm bases and the mantle, the head area can rise vertically or flatten. The immediate head area can bob up and bob down. These are different actions and likely controlled by different muscles, though there has been no specific research on the control of this area.

Mouth. The beak can hold in a gape or bite prey to remove and break down tissue (Altman \& Nixon, 1970). The radula can rasp or rest (Nixon, Maconnachie, \& Howell, 1980). The salivary papilla can poke into a hole that is being drilled into a shell (Nixon, 1980), or retreat. These behaviors are seldom seen, as the structural units are under the arm web (see Uyeno \& Kier, 2007, for buccal mass musculature and 'muscle articulation'), but their actions are assumed from muscle structure and prey damage.

\section{Combinations of One to Two Behavioral Units: Action Components}

\section{The Following Behaviors Involve Water Flow Through the Mantle-Funnel Complex}

Ventilation. This action is an alternating series of (a) mantle inflation with folding of the funnel tip and open mantle slits and (b) mantle deflation with unfolding of the funnel tip and closed mantle slits (see supplementary video two of E. dofleini). Both the period of this cycle and the amount of mantle contraction can vary (Wells \& Smith, 1985).

Posterior jet. This posture is the most similar to Standard position. The mantle inflates and then deflates, once or several times (Packard \& Sanders, 1971). Arms trail loosely posteriorly (see supplementary video three of $O$. vulgaris). There is cross species variation in their posture; in $O$. insularis and $O$. vulgaris the distal tips are bent and splayed, in E. dofleini the arm array is somewhat splayed and dorso-ventrally compressed, and the web is partly flared between the lateral second pair of arms and the nearest pairs. Assuming this position with a flattened surface would also allow the animal to resist sinking. Usually this is a short-term antipredator action (Hanlon, Forsythe, \& Joneschild, 1999, for O. cyanea).

Anterior jet. This action is attributable to expulsion of a jet of water from the mantle cavity, similar to posterior jet, but the octopus moves anteriorly; it is used for visually guided prey capture. The funnel is deflected so that the water jet is aimed to the posterior and the mantle deflates, so the octopus moves due to its jet of water. The proximal arms are ventrally directed, the rest of the arms trail posteriorly and are sometimes appressed to one another. Huffard (2006) describes this as 'forward-jet propulsion.' If this posture is maintained it is sometimes described as a "flounder-like swimming" and a mimic of these fish for T. mimicus (Norman \& Hochberg, 2005; Hanlon et al., 2008), though also see Macrotritopus defilippi (Hanlon, Watson, \& Barbosa, 2010) and an evaluation of the potential mimicry by Huffard et al. (2010). In capture, the arms splay as the animal approaches a target and the web flares prior to landing and capturing the prey item, thus marking the end of the action. Then the arms and web may move to midline, stalks 
move from and suckers grasp. The shape of arms and web will be dictated by the surface to which they adhere, including whether the item is in midwater or on the substrate.

Remove. Mather and Mather (1994) called this 'water jet,' but this leads to confusion with the other Jet terms. Thus, we define this action as the result of water outflow through the mantlefunnel complex to move something externally, not to produce movement of the animal itself. The funnel is deflected during the deflation phase, and a jet of water is aimed at some item (see supplementary video four of $O$. vulgaris). The item may be part of the environment such as sand, another animal including potential predators, or eggs being tended. As the mantle cavity is the fundamental interface between the internal organs and the environment, other substances besides water are moved, including ink ejected from the ink sac, spermatophores (see Mating), eggs to be attached to the substrate or held in the arms, or waste ejected from the anus and the renal papilla. The mantle strongly deflates. Arms can be splayed, depending on what is being acted upon, and some suckers grasp some surface (otherwise the jet would simply move the octopus backward).

\section{These Actions Involve Movement of the Head or Mantle}

Head bob. Only the head itself moves vertically in relation to the body, an up-down action, possibly repeated a few times (Mather \& Mather, 1994; Packard \& Sanders, 1971), as is seen in O. joubini and O. rubescens. The body is held stationary with arms somewhat splayed and middlearm suckers grasping the substrate (see supplementary video five of A. aculeatus). The mantle can be oriented up or down and may be inflated or deflated. This action produces motion parallax, which is used as a visual cue (Goldstein, the distal tips are bent and splayed, in $E$. dofleini the arm array is somewhat splayed and dorso-ventrally compressed, and the web is partly flared between the lateral second pair of arms and the nearest pairs. Assuming this position with a flattened surface would also allow the animal to resist sinking. Usually this is a short-term antipredator action (Hanlon, Forsythe, \& Joneschild, 1999, for O. cyanea).

Anterior jet. This action is attributable to expulsion of a jet of water from the mantle cavity, similar to posterior jet, but the octopus moves anteriorly; it is used for visually guided prey capture. The funnel is deflected so that the water jet is aimed to the posterior and the mantle deflates, so the octopus moves due to its jet of water. The proximal arms are ventrally directed, the rest of the arms trail posteriorly and are sometimes appressed to one another. Huffard (2006) describes this as 'forward-jet propulsion.' If this posture is maintained it is sometimes described as a "flounder-like swimming" and a mimic of these fish for T. mimicus (Norman \& Hochberg, 2005; Hanlon et al., 2008), though also see Macrotritopus defilippi (Hanlon, Watson, \& Barbosa, 2010) and an evaluation of the potential mimicry by Huffard et al. (2010). In capture, the arms splay as the animal approaches a target and the web flares prior to landing and capturing the prey item, thus marking the end of the action. Then the arms and web may move to midline, stalks move from and suckers grasp. The shape of arms and web will be dictated by the surface to which they adhere, including whether the item is in midwater or on the substrate.

Remove. Mather and Mather (1994) called this 'water jet,' but this leads to confusion with the other Jet terms. Thus, we define this action as the result of water outflow through the mantlefunnel complex to move something externally, not to produce movement of the animal itself. The funnel is deflected during the deflation phase, and a jet of water is aimed at some item (see 
supplementary video four of $O$. vulgaris). The item may be part of the environment such as sand, another animal including potential predators, or eggs being tended. As the mantle cavity is the fundamental interface between the internal organs and the environment, other substances besides water are moved, including ink ejected from the ink sac, spermatophores (see Mating), eggs to be attached to the substrate or held in the arms, or waste ejected from the anus and the renal papilla. The mantle strongly deflates. Arms can be splayed, depending on what is being acted upon, and some suckers grasp some surface (otherwise the jet would simply move the octopus backward).

\section{These Actions Involve Movement of the Head or Mantle}

Head bob. Only the head itself moves vertically in relation to the body, an up-down action, possibly repeated a few times (Mather \& Mather, 1994; Packard \& Sanders, 1971), as is seen in $O$. joubini and $O$. rubescens. The body is held stationary with arms somewhat splayed and middlearm suckers grasping the substrate (see supplementary video five of A. aculeatus). The mantle can be oriented up or down and may be inflated or deflated. This action produces motion parallax, which is used as a visual cue (Goldstein, 2002) to pinpoint the distance to an object of interest more clearly for an animal that has mostly monocular vision (Byrne, Kuba, Meisel, \& Griebel, 2002).

Rise/Flatten. The body is moved vertically with relation to the substrate, likely by bending and contraction of the arms moving from more or less splayed, which raises or lowers the head (Mather \& Mather, 1994; Packard \& Sanders, 1971; see supplementary video six of E. dofleini). During this time there is sliding or sequential contact of suckers with the substrate, in grasp/release. Many octopuses, for example, O. vulgaris and O. cyanea, perform this action at the den (referred to as the "home" in Mather, 1994) entrance before leaving.

Mantle-bounce. A mating display seen in both sexes where the body is held upright, likely with the arms down, and the mantle is raised and lowered every few seconds (Huffard, 2007a). This has been described only in A. aculeatus.

Stand tall. The head rises off the substrate with the mantle held relaxed and downward. The arms are somewhat extended and splayed on the ground, with the distal suckers grasping the substrate, similar to what Packard and Sanders (1971) called "Standing." An octopus raises the head by moving away from the substrate. The web can be somewhat flared symmetrically. This is a relatively static posture, often as the octopus rises to examine an object of interest such as a conspecific, in E. dofleini, O. vulgaris, O. cyanea, A. aculeatus (Huffard, 2007a). The posture may be exaggerated by the extended eyes in $W$. photogenicus and is especially obvious in $T$. mimicus (Hanlon et al., 2008).

\section{These Actions Involve Extensive Flaring of the Web}

Dymantic posture. (fides Packard \& Sanders, 1971; note it is also included in the category deimatic by Hanlon \& Messenger, 1996, which is a wider category of purpose and not a physical position). In this stereotyped posture, the proximal arms are splayed maximally and extended, the distal 1/3 or more bent to the posterior. The web is maximally flared between all arms, and the relatively flat surface thus formed may be oriented toward the source of threat, as it is 
primarily used as a defensive startle display (Packard \& Sanders, 1971). In T. mimicus, the web is minimally flared (Norman \& Hochberg, 2005). The mantle may be held inflated and the skin is smooth. The display that often accompanies this is a general paling or blotch, with dark contrasting arm suckers, frontal hood and eye bars (Mather \& Mather, 1994).

Webover. The web is flared between extended arms, but pressed against some aspect of the environment (e.g., a rock; Mather, 1991, 1998). The web areas might not all flare the same amount or at the same time. The distal tips of the arms are bent toward the midline but in no particular pattern, and they explore the substrate around and underneath the item, so the suckers grasp and release (Mather, 1991; Mather, 1998). The head is often held in rise. Although the octopus' position is static, parts of the arms move with relation to the environment. A similar posture sometimes occurs in the water, when the web and arms act as a kind of net, in $E$. dofleini, but also in deep sea cephalopods unable to use vision for finding prey (Cosgrove, 2003; Voight, 2005, 2008).

\section{These Are Actions of the Sucker-Stalks Only}

Conveyer belt. With an extended arm, a small object of interest is grasped with a sucker at the distal tip, the stalk presumably moving it away from the arm (Mather, 1998). Only suckerstalks move, as the object is passed from sucker to sucker, stalks turning and suckers grasping and releasing as it is moved. The direction is typically toward the proximal end of the arm and into contact with the mouth. Other arms are somewhat splayed and their middle arm suckers may grasp the substrate (Mather, 1998).

Tiptoe. Only the sucker-stalks of the proximal arm area move, though all arms are typically used (Mather, 1998). The distal 2/3 of the arms is not involved but is either tucked under the body or trails passively after the active areas (see supplementary video seven of $E$. dofleini). The head is held in rise above the substrate (e.g., O. joubini, E. dofleini).

\section{These Are Actions of Arms, Stalk, and Suckers}

Push/Pull. Suckers of the middle to distal regions of the arm grasp and stalks extend (Mather \& Mather, 1994; Mather, 1998). While this adhesion is continued, the arm performs a combination of extend/contract, splay or move to midline, bend, and/or twist, thereby changing the distance and the orientation of the item with relation to the body of the octopus. This set of actions can be used to bring a prey item closer to the mouth or to manipulate the substrate in situations such as digging in sand and cleaning out dens. This may be carried out by one arm, or multiple 'neighboring' arms can be recruited (Byrne et al., 2006).

Groom. This is a simple arm action where arms move across the skin in a complex unpredictable spatial pattern, in contrast to mice, for which grooming has been described as a set of stereotyped motions (Golani \& Fentress, 1985). Octopuses pass the arms over their body surface, using the distal 1/3 of the left and right anterior arms (1L and 1R; Mather, 1998). As the arms move in an undulating pattern, the sucker-stalks move to and move from the arm, the suckers grasp and release (see supplementary video eight of $O$. vulgaris). The effect is to clean the surface. There is no fixed sequence of events or set patterns of movement. The arms can groom the outer skin, within the mantle cavity, or the eggs when females are caring for them 
(see supplementary video nine of $O$. vulgaris). This action presumably removes ectoparasites from the body and settling algae and fungi from the eggs (Mather, 1998).

Sucker skin removal. Each arm bends and sometimes twists to rub against its own oral surface, in a kind of writhing series of bends that helps to remove dead skin from the suckers (referred to as 'cleaning maneuver' in Packard \& Sanders, 1971). The location of maximal bending can travel up and down the arm or can remain equal along it, but arms perform this action separately, although simultaneously (see supplementary video 10 of E. dofleini). Some species, such as $\mathrm{H}$. lunulata, perform this action without surface contact, 'shaking a set of loops.'

Mate. Males generally approach females, with the traditional view that enlarged proximal sucker display in some octopus species is involved (Packard, 1961; Voight, 1991a). Recent discoveries are unraveling the interconnected role of various chemical signals (see Polese, Bertapelle, \& Di Cosmo, 2015, Table 1) with multiple nervous centers including the olfactory lobe in controlling reproduction. Male octopuses can (a) mount the female dorsally and envelop her in webover or (b) extend the third right mating arm called the hectocotylus from a distance (see Hanlon \& Messenger, 1996, Table 6.3; more recent information from H. Iunulata [Cheng \& Caldwell, 2000]), A. aculeatus (Huffard et al., 2008), O. tetricus and A. marginatus (Huffard \& Godfrey-Smith, 2010), O. bimaculoides (Mohanty, Ojanguren, \& Fuiman, 2014). These positions can vary from species to species or both may occur within one species. Mather (1978) found that the mating posture in $O$. joubini varied depending on whether the animals were moving freely or confined in a small aquarium, emphasizing the importance of looking for examples in their natural environment. Additionally, the Larger Pacific Striped Octopus has been noted to mate 'beak to beak' (Rodaniche, 1991; Caldwell et al., 2015). The male's third right arm is modified with a special tip and a groove down its length. The penis (or terminal organ; Wells, 1978) extrudes a spermatophore (sperm sac) with thousands of sperm inside (Mann, 1984), pushed by a modified remove called arch-and-pump (Wodinsky, 1973) to lodge in the sperm groove and move down the arm. The distal tip of the arm finds the opening of the female's oviducal gland to deposit the spermatophore at the entrance and sperm are pushed into the oviducal gland. Various spermatophore transfer movements and their function have been described by Wodinsky (2008). The erectile tissue at the tip of the third right arm has been shown to function as a muscular hydrostat in $O$. bimaculoides, suggesting a potential mechanism for its role in reproduction (Thompson \& Voight, 2003). Male sexual skin displays may be present, as seen in O. cyanea, A. aculeatus, and Amphioctopus marginatus (see the Male Sexual Displays section below).

Flamboyant posture. This is a stereotyped cryptic posture usually seen in young octopuses (Packard \& Sanders, 1971; O. vulgaris, E. dofleini, A. aculeatus, O. chierchiae) and presumed to be matched to the visual system of observers, who are typically fish. The arms are held splayed, bent upward and toward the posterior, and the dorsal arms may also be twisted in a helix, especially distally. The mantle may be held in an ogive posture, with the skin color varying. The papillae are raised and the body rises somewhat from the substrate.

Retroflex. The arms are splayed equally, separated from one another, and bent back toward the posterior so that the suckers are uniformly presented (Packard \& Sanders, 1971). This can be a protective posture when the octopus is out in the open, but is more likely with attachment to surfaces in shelter. In bivalve shells, the animal (O. joubini and juveniles of larger species) 
presents the arm bases toward one valve, bends the arms back so that arm midline falls on the inside of the other valve and adheres to them, pulling the valves shut tightly. Many times in shelter the arm base suckers grasp rocks or shells to form a closure of the opening (Mather, 1994). An alert animal in shelter may pivot this structure so a single eye peers out from underneath a circular bent arm.

Oppose. Similarly to retroflex, the arms are splayed and bent somewhat to the posterior (Mather, 1998). However, the proximal suckers of the ventral arms hold to the substrate, while the dorsal arms bend back to the posterior, which would display enlarged suckers of mature males (see supplementary video 11 of $O$. vulgaris as it starts to jet). During male 'fighting' (O. vulgaris, O. joubini) and females repelling males, conspecifics may line up their arms against each other and push in an attempt to straighten. A successful individual in oppose could begin to do webover, whereas an unsuccessful one would end up in retroflex, and likely squeeze out from under the arm web and escape.

Crawl. This is a complex action based on push-pull and has also been referred to as 'walk' (Mather, 1998). The octopus moves across the substrate by pulling on the 'leading' arms and pushing with the 'trailing' ones (Cowdry, 1911; Mather \& Mather, 1994; Packard \& Sanders, 1971), probably adhering to the substrate with the grasp of middle-arms suckers at multiple points (see supplementary video 12 of $O$. cyanea). The identity of leading and trailing arms depend on the direction of motion as well as arm identity, although the 3rd and 4th arm pairs are likely to contact the substrate as the 1st and 2nd pairs explore (Mather, 1998). With increasing interest in the octopus as a soft robotics model, gait patterns and arm-sucker coordination have been under investigation (Calisti et al., 2011). Levy, Flash, and Hochner (2015) found, in contrast to vertebrates and insects (Alexander, 2003), no predictable sequence of arm recruitment for crawling. A. marginatus (Huffard, Boneka, \& Full, 2005) and A. aculeatus (Huffard, 2006) employ a wide variety of crawling gaits including bipedal walking. Hanlon, Forsythe, and Joneschild (1999) discuss a modified crawling behavior called 'moving rock' in O. cyanea where the arms and web are spread, the head is flattened, and the octopus moves around slowly, only using the distal ends of all eight arms.

Explore. This is a multiarmed but uncoordinated set of actions interspersed or combined with crawl that usually involves a chemotactile search (Mather, 1998). Arms extend across the substrate or into crevices and through rubble, bending to suit the topography (see supplementary video 13 of A. aculeatus). Guided by chemical and tactile cues, stalks of the distal arm suckers move to, move away from and turn, while suckers grasp and release (Mather, 1998). When an item is found, the suckers hold. Arms may retract and bend to remove prey from attachment. They continue these actions as the suckers continue holding, and arms bend and twist to move the item toward the proximal suckers or to the mouth for Prepare. Recruitment of neighboring arms is common, and small prey may be held by suckers of proximal arm areas in grasp as the octopus continues to hunt for more (Yarnall, 1969). This action may also involve web over.

\section{Combinations of Three or More Behavioral Units: Action Patterns}

Prepare. Generally stationary in shelter, an octopus deals with preparation and consumption of the prey items, with several actions sequentially (Anderson \& Mather, 2007). Arms may bend 
toward the midline, and suckers of the proximal arms hold the prey in grasp. For opening valves of bivalves, the clam is held umbo (at the dorsal edge where the valves hinge) toward the mouth while proximal suckers of arms grasp and the arms, half on each valve, attempt to bend/splay, thus pulling the shells apart. For prey that resists a pull (Steer \& Semmens, 2003), including strong bivalves, gastropods, chitons, and even major claws or carapaces of crustaceans, the octopus may drill a hole, alternating poking with the salivary papilla and rasping with the toothed radula (Nixon, 1980). Chipping at the edge of a valve by biting with the beak also allows posterior salivary gland toxin to be injected. This weakens the bivalve's adductor muscle which holds the two valves together, facilitating the shell being pulled apart. Less resistant prey is simply bitten, and killed by the toxin. The rasping radula strips tissue from skeleton or shell, and the suckers of the proximal $2 / 3$ of the arms hold the pieces of shell or skeleton. When the prey is consumed, the spread arms tilt up, the suckers release and the octopus deflects the funnel to send a water jet and propel remains out of the shelter.

Egg lay. A female passes eggs from the ovary down the oviduct, and they are given a coating by the oviducal gland. Here the sperm are released and reactivated to fertilize the eggs (Mangold \& Von Boletzky, 1973). These eggs are passed through the funnel into the area under the proximal arms by funnel deflect and mantle deflate, and in some species (e.g., E. dofleini) the egg stalks are woven into strings by the movement of the sucker stalks in the proximal arms region near the mouth. The bases of the egg stalks are commonly adhered to the shelter in which the octopus hides, although some species, like Hapalochlaena sp. (Dew, 1959; Tranter \& Augustine, 1973) and W. photogenicus (Huffard, Gentry, \& Gentry, 2009; Miske \& Kirchhauser, 2006) hold the eggs with their suckers or in their ventral web (as in Amphioctopus aegina (Promboon, Nabhitabhata, \& Duengdee, 2011). Then the mother begins the process of guarding, grooming, and aiming water jets at the eggs (Vevers, 1961).

Sleep. Although this is not strictly speaking an action, it is a set of muscle parameters and postures. The linear pupils of the eyes are closed, muscles of the chromatophores are relaxed so color is pale, arm muscles are relaxed, and the animal is unreactive (Meisel, Byrne, Kuba, \& Mather, 2011). The skin pattern Half and Half (to be described in the following section) may appear.

\section{The Skin Display System}

Although its 'purpose' is to present the animals' appearance, changes in the display system are based on motor control and so are examined in the assessment of cephalopod movement. There are four structures (elements) in the system: chromatophores and deeper reflective cells in the skin, textural structures from papillae, and postural components covered in Actions (see Messenger, 2001). Chromatophores are elastic skin sacs that contain black (or brown), red, orange or yellow pigment that are expanded by contraction of a system of radial muscles to make the colors visible, like color pixels on the skin. Direct neural control to the muscles means that colors can be changed in as short a time as $30 \mathrm{~ms}$, and in areas as small as a square $\mathrm{mm}$. Packard (1995) has made a lifetime study of the system. When the chromatophores are all contracted, leucophores and iridophores below reflect light; leucophores reflect the ambient wave lengths around the animal and iridophores reflect in the blue-green region of the visible light spectrum (Packard \& Hochberg, 1977). Leucophore reflection is responsible for the conspicuous white spots seen in many octopus species (Packard \& Sanders, 1971). The 
iridophore subsystem is not completely passive, as hormonal modulation allows the reflective layer to partially 'aim' and change the spectral color along the blue, green and violet range (Cooper, Hanlon, \& Budelmann, 1990, for squid). Reflection of iridophores is responsible for the blue rings of the Hapalochlaena species (Mäthger, Bell, Kuzirian, Allen, \& Hanlon, 2012), for ocelli in some species, for example, O. bimaculoides (Packard \& Hochberg, 1977), and for polarization of light when reflected at oblique angles (Mäthger, Denton, Marshall, \& Hanlon, 2009; Moody \& Parriss, 1960). Despite this range of color production, most cephalopods have only one photopigment and so are color blind (Messenger, 2001), but cuttlefish nevertheless produce a good color match for the eyes of fish predators (Chiao, Wickiser, Allen, Genter, \& Hanlon, 2011). The textural component of the appearance system is an array of muscles under the skin which raise it in the form of single papillae (see Allen et al., 2013, for cuttlefish). Papillae pit locations are diagrammed in some species descriptions and field observations (Roper \& Hochberg, 1988; Hanlon \& Hixon, 1980). Large supraocular papillae, often called 'horns,' are raised above the eye. The postural aspects of the appearance system are somewhat stereotyped, and variation is found particularly in young octopuses (Packard \& Sanders, 1971), who are at risk from a wider range of predators.

An a priori assumption is that the skin is a two-dimensional area. Following the hierarchical concepts outlined by Packard and Hochberg (1977), units, which are composed of elements in different areas of the skin, would produce Components which, when displayed together, would make Patterns. These were vividly described in Hanlon and Messenger (1988) for Sepia cuttlefish. Component combinations have been analyzed statistically for $O$. insularis by Leite and Mather (2008), as well as for the cuttlefish system by Crook et al. (2002). But this combination approach is only part of the story. A chromatophore lobe of the brain directly innervates the skin. Froesch (1973) described the projection of chromatophore nerves onto the surface of the octopus skin, and found that unit areas were smaller dorsally and around the head region. However, recording from the brain lobe did not result in the representative spatial projection onto the skin that is the case for vertebrate brains (Zullo, Sumbre, Agnisola, Flash, \& Hochner, 2009). Stimulation of the optic lobe near the eye may result in whole skin pattern output, and see Grasso (2014) for an argument as to why we should not expect this spatial array in the brain. Packard (1995) describes local electrical spreading, and Leite and Mather (2008) found that the different units of pattern, known as 'expressive fields,' did not necessarily match the areas of neural projection.

The difficulty of understanding appearance in the octopus is compounded by the fact that control is not at a single level. First, modulation of average skin appearance is partially attributable to the level of illumination and hormonal levels, as has been described in cuttlefish (Ferguson, Messenger, \& Budelmann, 1994), and seen in O. insularis (Leite \& Mather, 2008). Cuttlefish produce countershading with dark coloration above and pale below; if one rotates the animal 180 degrees, the shading is reversed. Octopuses may show such modulation, and animals in deeper water have darker skins. Such chronic color modulation is reflexive, not under voluntary control.

A second level of control and type of modulation is demonstrated in camouflage. Production of this match to the local environment is excellent, and involves chromatophores, papillae and postures. A series of studies by Hanlon and associates and Osorio and his team 
have shown that camouflage of cuttlefish is the result of careful assessment of the visual features of the background on which they are placed (see recent review in Chiao, Chubb, \& Hanlon, 2015). Such assessment, although not 'conscious,' involves sophisticated perceptual analysis of contrast and edges in the environment. Cephalopods use a wide variety of camouflage solutions in their heterogeneous benthic environment, for example, using general resemblance or matching feedback, and many parameters have been studied, particularly in cuttlefish, to quantify the effectiveness of these solutions (Josef \& Shashar, 2014). Octopuses camouflage as well as cuttlefish, and perhaps use the same level of analysis. Predator presence is a major stimulus for pattern change for Robsonella fontaniana (Ruiz, Sepulveda, \& Ibanez, 2012) and Hanlon et al. (1999) consider unpredictable changes in pattern by escaping octopuses, rather than static background matching, to be the primary antipredator tactic in $\mathrm{O}$. cyanea.

A third and probably 'voluntary' level of control of the displays utilizes the changes in chromatophores, leucophores, iridophores, papillae, and movement in the structural units to 'build' appearance (see examples following). It is at this level that variable chromatophore contraction patterns are assembled which may produce species-specific patterns (see Hanlon, 1988) and situation-specific ones. Intensity of particular components can be modulated locally or generally, both by unit intensity and background contrast (see Mäthger et al., 2012, for brown contrast with the blue rings of $\mathrm{H}$. Iunulata and Buresch et al., 2015, for varying camouflage intensity in relation to substrate in cuttlefish). The fact that the cephalopod body plan is bilaterally symmetrical is reflected in the expression of a Half and Half display. Octopuses aim a Passing Cloud (Mather \& Mather, 2004, for O. cyanea) to 'move' posterior to anterior to startle a crab into moving. This display, also seen in cuttlefish and other octopus species, transcends any idea of static spatial components. A recent study by Laan, Gutnick, Kuba, and Laurent (2014) offers one of the first approaches to studying passing cloud patterns in the cuttlefish Metasepia tulbergi by analyzing them as the propagation of traveling waves. Components can also vary in the amount of skin on which they are displayed. Squid modulate the intensity, area and direction of the agonistic Zebra display, and direct it toward a rival (Mather, 2004). Similarly, the White Papillae sexual display of male O. cyanea can appear over all the skin surface, a specific area such as the half facing toward the female, or only the third right arm (Mather, 2004).

Around the localized components of the body pattern is a base color on the skin. There are no known wavelength recordings of reflected light from the base pattern of octopuses, although see Chiao et al. (2011) for cuttlefish. The base or background color can be displayed on most or all of the body surface (if only part, possibly only mantle-head or arms). Some species such as W. photogenicus, T. mimicus (Norman \& Hochberg, 2005), and O. chierchiae have semipermanent striped patterns (Rodaniche, 1984), O. zonatus and O. motati have semipermanent black and white bands (Hanlon \& Messenger, 1996), and O. macropus and Callistotopus ornatus have white spots on a brown background (see Roper \& Hochberg, 1988). The following are typical base colors or patterns.

\section{Combinations of Chromatic and Textural Units: Skin Display Components}

Background. The background is relatively homogeneous and extensive (at least half the body). It can be the expansion of all one color set of chromatophores (brown/black, red, orange, yellow). For example, brown color can come from expansion of all brown chromatophores. Background can also result from homogeneous expansion of more than one 
chromatophore type, such as the expansion of yellow and brown chromatophores making a yellowbrown color). It can also be made of large areas with different chromatophore type expansions. Large areas of all chromatophore contraction gives white.

Figure 2. Diagram of localized skin display components including spot, blotch, stripe, bar, and ring. Arrows indicate direction (anterio-posterior, and lateral) of chromatophore expansion to make localized components. Note the majority of expansion in stripe and bar are in one direction, though small amounts of change can occur in the perpendicular direction. See the online article for the color version of this figure.
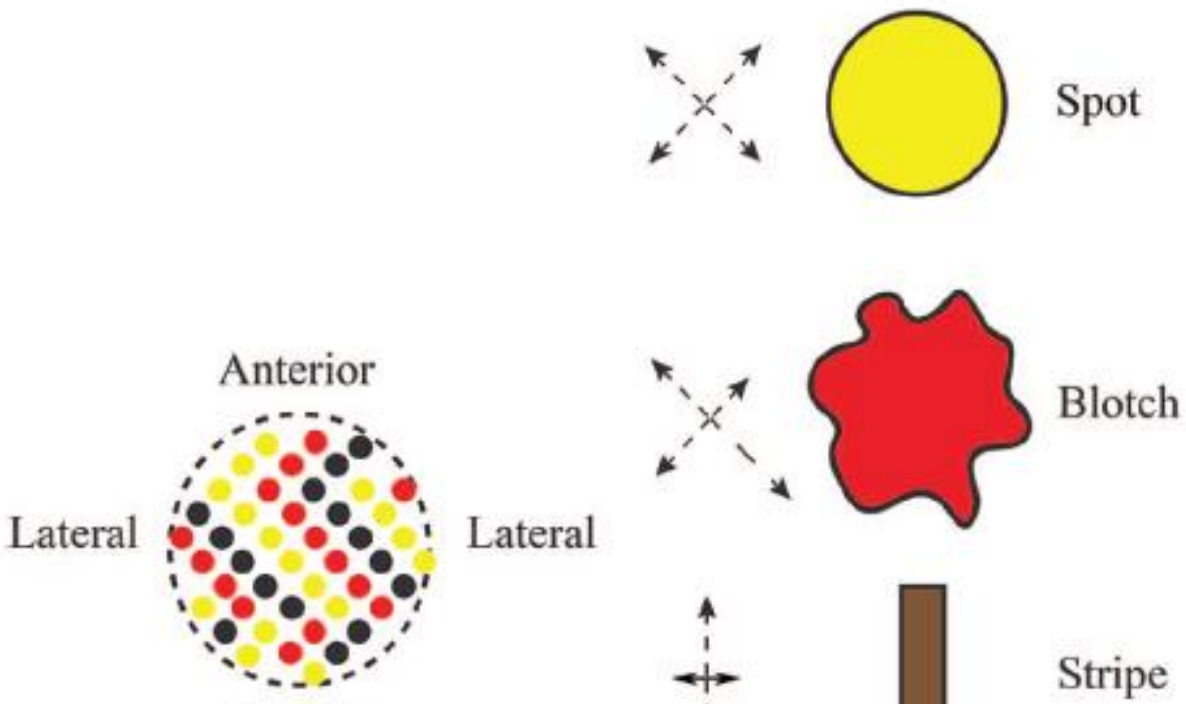

Posterior

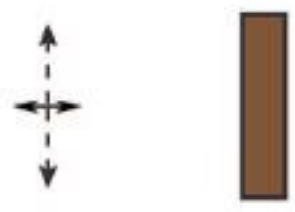

\section{Stripe}
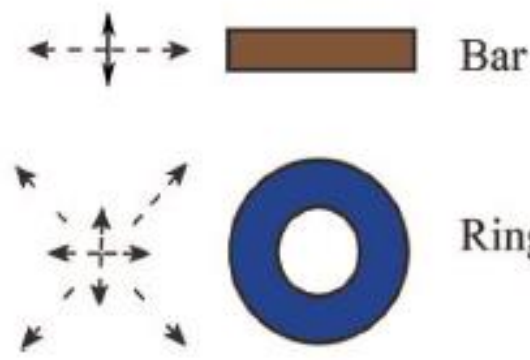

Ring

Localized area. Localized areas have relative chromatophore expansion in a field of 360 degree around a theoretical center point. These are in contrast to the background around them (see Figure 2). All are defined by relative extensions in two dimensions and vary in number from a single, a few, or recurring components that may or may not be repeated in a set pattern.

Spot. Found in various locations on the body and often referred to as white spot (Packard \& Sanders, 1971), it is an area extending equally in all 360 degrees of the dimensions. Unlike Octopus, other cephalopods also have dark spots (e.g., Sepia pharaonis, Okamoto, Mori, \& Ikeda, 2015). Spots are sometimes in a definite location (i.e., eye-spot) and are sometimes multiple, like the paired spots on the mantle/arms of O. vulgaris (Packard \& Sanders, 1971) and 
the series of spots running down the arms of the O. macropus complex (Voss \& Philips, 1957) and O. cyanea.

Blotch. An area averaging approximately equal but not uniform expansion (Mather \& Mather, 1994; Packard \& Sanders, 1971). More than one blotch can occur in a localized area of the skin, for example, on the mantle. Some are the same shape, some are different, like the individually identifiable blotches of W. photogenicus (Huffard et al., 2008). Hood: Dark area around the eyes that extends variably down the arm bases (Packard \& Sanders, 1971). Cloud: Dark area with surrounding white.

Stripe. An area extending in the anterior-posterior direction at least three times the extent in the lateral direction (longitudinal stripe in Cowdry, 1911; Mather \& Mather, 1994). It can consist of side by side pale and dark stripes extending along mantle, head, and proximal arms (Cowdry, 1911). Several stripes can also occur along the mantle, head, and/or arms, often, though not always in specific positions. Pale medial stripe: Pale area on a contrasting dark background from head to proximal head and mantle (A. aculeatus in Huffard, 2006) that can vary in width. This is similar to what Forsythe and Hanlon (1988) called 'white longitudinal center stripe.'

Bars. An area extending in the lateral direction at least three times the extent in the anteriorposterior direction. Many equal bars can often occur along the arms $(O$. insularis; Leite \& Mather, 2008) or all over the body (O. chierchiae) either regularly or variably in location. In these examples, dark bars are repeated on a white background. Eye bar: area extending from the ends of the elongate pupil of the eye (Cowdry, 1911; Packard \& Sanders, 1971).

Ring. Coordinated chromatophore expansion and contraction in all 360 degrees similar to a spot, but leading to expression only in an outer concentric region all over the skin. Ocellus: paired on lateral arm bases, usually blue when exposed (Packard \& Hochberg, 1977). Eye ring: (Packard \& Sanders, 1971) around the eye, sometimes incomplete in an arc (O. rubescens). Recurring blue rings: Also known as 'iridescent blue rings' (Roper \& Hochberg, 1988), they range in intensity, are found all over skin but mostly on the paler ventral mantle. The appearance of these rings can be modulated from pale to conspicuous and this can vary all over the skin (Mäthger et al., 2012).

Reticulate. Many small components with the same relative difference in dimensions as stripes and bars but oriented in no specific direction, seen as a dark 'spider-web' on a paler background (Cowdry, 1911; Mather \& Mather, 1994).

Papillae. In raised papillae, a collection of individual papilla units stand up on specific areas of the skin, see a diagram for O. burryi (Hanlon \& Hixon, 1980). Papillae are muscular hydrostats in cuttlefish (Allen et al., 2013), and in octopus (Allen, Bell, Kuzirian, Velankar, \& Hanlon, 2014). They can be categorized as primary papillae, which are large and consistently expressed, or secondary papillae, which are smaller and not often shown (Roper \& Hochberg, 1988). Primary papillae can also be characterized by shape, as conical (e.g., O. vulgaris, O. bimaculoides, and A. aculeatus), flattened (Mather \& Mather, 1994; Packard \& Sanders, 1971; e.g., O. vulgaris, E. dofleini, O. cyanea), and compound (see Allen et al., 2014, for all examples). This aspect of skin appearance is primarily found in the second level of control, to assist patterns in resemblance to the background (Mather, 2004). 


\section{Combinations of Components: Skin Patterns}

Mottle. Initial descriptions (Cowdry, 1911; Mather \& Mather, 1994; Packard \& Sanders, 1971) suggest the pattern is used for background matching, consisting of many small localized spots and blotches, varying in background, size and extent with no perceivable patterns, sometimes with raised papillae (O. cyanea). Mottle is not obviously predictable and the mix of components could be individual or species-specific.

Dymantic. The dymantic posture occurs with this skin appearance. The skin components can be species-specific but usually consist of the following stereotyped components exemplified in O. vulgaris (Packard \& Sanders, 1971): white background sometimes with multiple blotches, reticulate, frontal hood, eye bar, and contrasting edges of suckers. Postural components include the proximal $2 / 3$ of arms splayed and bent posteriorly with the web flared. It is assumed to be a startle display. This has been suggested as a parallel display to those of the cuttlefish and squid, with darkening on the white background (Moynihan, 1975).

Flamboyant pattern. Some combination of spots, blotches, stripes, bars, and usually raised papillae, accompanied by components of the flamboyant posture described earlier.

Camouflage. A variety of localized patterns is possible-spots, blotches, stripes, bars. The background color usually matches the local environment. Other components can include eye bar, eye ring, or white $V$ on the dorsal arm bases (Packard \& Sanders, 1971). Textural components include raised papillae if the background is textured. A possible postural component is flattened.

Half and half. Dividing the animal along the midline, each half of the skin expresses a different pattern, often contrasting dark/pale (O. vulgaris, E. dofleini; Mather \& Mather, 1994). It has no known function and is seen in sleep (Meisel et al., 2011), so it may be random neural output, though it could convey two messages, as in sexual attraction and antipredator ones for squid (Mather, 2004).

Passing cloud. This is an apparent movement (see Goldstein, 2002, the pigmented area does not actually move) produced by sequential expansion and contraction of chromatophores moving one or a few clouds, starting in the posterior and moving along mantle, head, and flared web to 'flow off' the edge (O. vulgaris in Packard \& Sanders, 1971; analyzed for $O$. cyanea in Mather \& Mather, 2004). The skin edges around a cloud are pale (see supplementary video 14 of $A$. aculeatus). It is commonly unilateral and is usually a startle directed to potential prey.

Resting displays. Specific patterns are seen when octopuses are in shelter (difficult to see), and they may be species-specific. $O$. insularis has gray green arms with purple suckers like $O$. vulgaris (Cowdry, 1911; Mather \& Mather, 1994), O. cyanea is whitishgreen, the Larger Pacific Striped Octopus has dark bars, stripes, and arm spots over a dark background (Caldwell et al., 2015) and W. photogenicus has high contrast dark brown, pale spots on the mantle and bars on the arms (Huffard et al., 2010). These also may act as camouflage.

Male sexual display. There has been a debate about whether the presence of enlarged suckers in the males (Packard, 1961; Voight, 1991a) and displays of the ligula, the tip of the 
male's third right arm (Voight, 1991b), are used in courtship. Although they remain inconclusive as visual displays, there is potential, especially for the enlarged suckers, to be used for sexual chemoreception. There are three described displays, all of which are accompanied by third right arm extension and probing into the female's mantle cavity by the male. O. cyanea has equally raised conical papillae that produce white spots on the outer $2 / 3$, with the surface of the skin brown (Mather, 2004). Male A. marginatus displays raised papillae with spread dorsal arms, contrasting white suckers to a dark purple edge along the arms (Huffard \& Godfrey-Smith, 2010). Though similar, it is not a typical dymantic display and it was suggested that variations seen in white sucker contrast may identify different genetic populations. In A. aculeatus, a contrasting black and white stripe ('BWS') along the mantle is a typical male body pattern, along with raised papillae (Huffard et al., 2008) that has also been seen during aggression to conspecifics (Huffard et al., 2008). Male contrast striping have been seen in other species such as in 0 . cyanea (Wells \& Wells, 1972) and Octopus horridus (Young, 1962), which was later corrected by Huffard (2007a) to be an unidentified Abdopus species from Singapore.

\section{Discussion}

Despite the many degrees of freedom resulting from eliminating physical constraints on octopod actions, octopus movement may be composed of a limited number of motor combinations produced by a few central programs or neural output 'rules' (Gutfreund et al., 1998). Thus, on the surface, many components of the movement and display systems can be described fairly simply and summarized in an ethogram. For instance, Messenger (2001) assumed there was an additive process in combining display elements to components and components to patterns, resulting in the description of 10 to 12 distinct display patterns found in each octopus species. A similar number was suggested for O. vulgaris by Packard and Sanders (1971), as well as calculated from component combinations for O. insularis (Leite \& Mather, 2008).

The simple array of central patterns that result in behaviors may be modified in their actual action outputs. For instance, the cephalopod brain is bilaterally symmetrical, and as a result components and even whole patterns (Packard \& Sanders, 1971; Mather \& Mather, 1994) may be displayed on only one side of the body. In $\mathrm{H}$. lunulata, the contrast of the blue rings against their background can vary unilaterally (Mäthger et al., 2012). Whole body patterns have been elicited by stimulation of the optic lobe in cuttlefish (Boycott, 1961) and the peduncle lobe and subsequent visuomotor complex in octopus (Messenger, 1967), but the components of these patterns in octopus have not been evaluated carefully to determine their neural underpinnings. Although we know skin displays are formed of chromatophore, local leucophore and skin papillation components (Messenger, 2001), the exact components have been seldom analyzed quantitatively in octopus (though see Leite \& Mather, 2008), although they have been for cuttlefish (see recent review by Chiao et al., 2015). Similarly, neural 'rules' may form the basis for movement patterns (as in Hochner, 2013) whose details are then matched to the demands of a particular environment. Microstimulation of the supraesophageal mass suggests that basic motor components, like those of the display system, can also be combined to create more complex movements, from localized responses to whole body locomotion (Zullo et al., 2009).

Also, display components are modulated. They vary in intensity of the display and also in background/component contrast (Mather, 2004). The Passing Cloud, for instance, is a pattern of chromatophore expansion, yet in $\mathrm{O}$. cyanea it is bordered by a narrow band of chromatophore 
contraction that produces a strong black-white contrast (Mather \& Mather, 2004). And although we assume that components would be expressed in the areas bounded by the projection of specific mantle nerves, Leite and Mather (2008) found that what they termed 'Expressive Fields' did not match the spatial extent of nerve projection; myogenic spread of contraction (Messenger, 2001; Packard, 1992) is suspected. The basic description of patterns detailed here is a good starting point to explore these connections.

The structural components described here may be recruited into several action patterns. The mantle-funnel combination has a basic function in molluscs of ventilation (Solem, 1974) as is also the case in cephalopods (Boyle, 1976), with modulation of frequency and intensity of contraction. However for squid, and to a lesser extent octopuses and cuttlefish, these units are recruited for fast escape response in the form of posterior-directed jetting (O'Dor \& Webber, 1986). Tertiarily, the octopus mantle-funnel combination expels water used to move items around, ranging from spermatophores to deposit in the third right arm groove for fertilization (Mann, 1984) to ink production confusing or repelling a predator (Wood et al., 2010) and also moving sand and gravel to clear out a sheltering den or 'home' (Mather, 1994). Conversely, different actions can be used to accomplish the same goal. Like fish (Sfakiotakis, Lane, \& Davies, 1999), octopuses use several gaits and recruit various body parts for locomotion, dependent somewhat on speed. The sucker-based tiptoe is slow and dependent on a smooth surface (Mather, 1998), whereas arm-controlled walking and crawling are faster (Mather, 1998) involving diverse postures adapted to various substrate (Huffard, 2006). The mantle-based jet propulsion both combines with crawling, as do fish fin beating and body bending (Alexander, 2003), and is used by itself for higher speed escape responses.

Given a description of what units of behavior occur, how can we evaluate the programs and constraints that control them? Particularly with the number of degrees of freedom that are possible for octopus arm movement, Flash and Hochner (2005) suggest that we should look for motor primitives, small prepackaged units woven into larger combination of actions. Such simple programs could be at the center of the components described here, as Flash and Hochner (2005) suggest that a propagating wave of bending is at the center of single arm reaching movements, and could form the core of an ethological unit. However Richter, Hochner, and Kuba (2015) recently found that, when given a constraint during reaching, octopus arms produce more flexibility in sterotypical bend propagations and more variability by using other less stereotyped arm patterns. Hanassy, Botvinnik, Flash, and Hochner (2015) also discovered that the stereotypical reaching motion consists not only of bend propagations alone, but also arm elongation. A comparison can be made with Pellis, Gray, and Cade's (2009) evaluation of the judder behavior of male crickets. They found that, despite a tilted substrate, crickets had the goal of moving parallel to the substrate and adjusting their leg posture to attain this goal (Pellis et al., 2009). A similar set of adjustments can be seen in the actions involved in swamp hens bringing food to the mouth (Pellis, 2011). These examples illustrate how constraints, whether of sensory end point or physical activity, also shape the actions of a repertoire, though detailed analysis is needed to capture them. Hochner (2013) presents the idea of Embodied Organization, the dynamic interaction between the central nervous system and peripheral programs of the arms with the sensory and mechanical systems and reciprocal effects by environmental inputs. He suggests that this underlies adaptive behaviors in octopuses, such as making temporary joints in the arm to bring food to the mouth. Using this approach with the 
behavioral components and patterns we describe in this ethogram allows us to look at the underpinnings of muscular hydrostat functions and dynamics. Of particular interest to the authors is the utility of mathematical theory to describe the dynamical principles that produce muscular hydrostat based movement patterns. Furthermore, these detailed descriptions of behavior will facilitate better understanding of octopus movement as a good model for the growing field of soft robotics (Calisti et al., 2011).

Apart from the programming behind the actions, what can we learn about the behavioral repertoire of the family Octopodidae? The species discussed appear to have fairly similar repertoires, although few have been investigated in great detail in the field (most recently Huffard, 2007a for A. aculeatus). Perhaps this is true because the well-studied species are similarly active predators in shallow-water benthic habitats. Most of them are diurnal, such as $O$. insularis (Leite \& Mather, 2008) and O. cyanea (Yarnall, 1969), or can shift their activity cycle facultatively, such as $O$. vulgaris (Meisel et al., 2006). Their display repertoires may contrast with those of nocturnal species like $O$. macropus, which has fairly consistent recurring spot pattern (Voss \& Phillips, 1957; Norman, 1992a), and O. joubini, which has a very limited display repertoire (Mather, personal observation). Similarly, Hanlon and Messenger (1996) suggest that cephalopods with more complex habitats may have greater display repertoires because there is a larger array of backgrounds they need to match. Barbato, Bernard, Borrelli, and Fiorito (2007) attempted to correlate this pattern richness with the size of chromatophore lobes in cephalopods, but since the control of body patterns involves an interconnected neural network, just one lobe may not control or even represent the diversity of patterns seen in a specific species. Full descriptions of actions based on the present ethogram may assist us in evaluating the patterns of repertoires.

Hanlon (1988) and Huffard (2007a) both suggested that identification of particular behaviors and body patterns for different species could be used in cephalopods as taxonomic characters. Based on our current limited knowledge, there are more similarities than differences across species, particularly for movement repertoires. Yet some components of display repertoires may serve as distinct characters. The exposure of iridophores concentrated in particular areas delineates the maculated or ocellate octopuses, although so far no one has found either a function or a phylogenetic background for the ocellus displays (Norman, 1992b). The patterns of blue rings are distinct for the members of the venomous genus Hapalochlaena and are hypothesized to be an antipredator warning display (Mäthger et al., 2012). Some species, such O. chierchiae (Rodaniche, 1984) and T. mimicus (Norman \& Hochberg, 2005), have semipermanent stripe patterns and in W. photogenicus and $H$. lunulata these body patterns are individually unique (Huffard et al., 2008). The authors suggest there may be species-specific sexual displays in the group, similar to those in cuttlefish and squid (Hanlon \& Messenger, 1996), but only three have been described in detail from field observations and in at least one may also be used in aggressive interactions during mating (Huffard, 2007a).

More direct field observations must be made to broaden what we know about octopus behavior. When the first author studied O. vulgaris in Bermuda in the 1980s, she noted that the display repertoire did not match that of $O$. vulgaris from the Mediterranean (Packard \& Sanders, 1971). They instead resembled Cowdry's (1911) description from the same location. At the time there was some doubt about the species identity of $O$. vulgaris from the Caribbean, so she 
published a short paper on the display repertoire (Mather \& Mather, 1994). When Leite identified $O$. insularis as a new species from the northern coast of Brazil (Leite, Haimovici, Molina, \& Warnke, 2008), both Leite and Mather were struck by the resemblance of the Bermuda animals to the new species. Subsequently Leite has been searching the Caribbean for $O$. insularis and has determined that it is often found in shallow water while the 'true vulgaris' is seen at greater depths (Leite et al., 2008), so body pattern differences may indeed predict species identity. Similarly with the cryptic species Enteroctopus in southcentral Alaska (Toussaint, Scheel, Sage, \& Talbot, 2012), body patterns may be useful predictors for differentiating species. A recent trip by the authors to Okinawa, Japan to film several hours of natural behaviors in tide pools revealed that morphologically, the octopus being observed is Abdopus, but it does not resemble the well described behaviors and skin patterns of A. aculeatus by Huffard (2007a). Genetic analysis is currently being done, but both authors' experiences suggest that direct field observation, emphasized by ethologists (Andrews, 2015; Drickamer et al., 1996), is important in revealing what look like and may very well be species differences, even before any formal analysis. This account underlines how little we know about octopod behavior. We see modal action patterns (sensu Barlow, 1968) expressed, yet there is much more to know. Laboratory research such as that outlined by Hochner (2013) and following the examples presented in Pellis et al. (2014) will begin to elucidate the neural, physical, and sensory background of the organization of the behaviors. Yet field observation is also necessary to build up the repertoires of particular species, and Huffard's (2007a) work is an excellent example. Using this ethogram as a template, researchers can work in different areas to complete a full comparative account of octopod behavior.

\section{Acknowledgments}

This research was supported in part by grant number 1246750 from the National Science Foundation. We thank Khalil Iskarous, the principal investigator for the aforementioned NSF grant, for his support and providing outside perspective to our ideas. We thank the members of the cephalopod community for sharing their videos and pictures and Sergio Pellis for his discussions. We dedicate this article to Roland Anderson, an important octopus animal behaviorist.

\section{References}

Alexander, R. McN. (2003). Principles of animal locomotion. Princeton, NJ: Princeton University Press. http://dx.doi.org/10.1515/9781400849512

Allen, J. J., Bell, G. R. R., Kuzirian, A. M., \& Hanlon, R. T. (2013). Cuttlefish skin papilla morphology suggests a muscular hydrostatic function for rapid changeability. Journal of Morphology, 274, 645-656. http://dx.doi.org/10.1002/jmor.20121

Allen, J. J., Bell, G. R. R., Kuzirian, A. M., Velankar, S. S., \& Hanlon, R. T. (2014). Comparative morphology of changeable skin papillae in octopus and cuttlefish. Journal of Morphology, 275, 371-390. http://dx.doi.org/10.1002/jmor.20221 
Altman, J. S. (1966). The behaviour of Octopus vulgaris Lam. in its natural habitat: A pilot study. Report of the Underwater Association of Malta, 1967, 77-83.

Altman, J. S., \& Nixon, M. (1970). Use of the beaks and radula by Octopus vulgaris in feeding. Journal of Zoology, 161, 25-38. http://dx.doi.org/10.1111/j.1469-7998.1970.tb02167.x

Anderson, R. C., \& Mather, J. A. (2007). The packaging problem: Bivalve prey selection and prey entry techniques of the octopus Enteroctopus dofleini. Journal of Comparative Psychology, 121, 300-305. http://dx.doi.org/10.1037/0735-7036.121.3.300

Andrews, K. (2015). The animal mind: An introduction to the philosophy of animal cognition. New York, NY: Routledge.

Barbato, M., Bernard, M., Borrelli, L., \& Fiorito, G. (2007). Body patterns in cephalopods: "Polyphenism" as a way of information exchange. Pattern Recognition Letters, 28, 1854-1864. http://dx.doi.org/10.1016/i.patrec.2006.12.023

Barlow, G. W. (1968). Ethological units of behavior. In D. Ingle (Ed.), The central nervous system and fish behavior (pp. 217-232). Chicago, IL: University of Chicago Press.

Betz, O. (1999). A behavioral inventory of adult Stenus species (Coleoptera: Staphylinidae). Journal of Natural History, 33, 1691-1712. http://dx.doi.org/10.1080/002229399299806

Borrelli, L., Gherardi, F., \& Fiorito, G. (2006). A catalogue of body patterning in Cephalopoda. Napoli, Italy: Firenze University Press.

Boycott, B. B. (1961). The functional organization of the brain of the cuttlefish Sepia officinalis. Proceedings of the Royal Society of London, Series B: Biological Sciences, 153, 503-534. http://dx.doi.org/10.1098/rspb.1961.0015

Boyle, P. R. (1976). Receptor units responding to movement in the octopus mantle. The Journal of Experimental Biology, 65, 1-9.

Boyle, P. R., \& Dubas, F. (1981). Components of body pattern displays in the octopus Eledone cirrhosa (Mollusca: Cephalopoda). Marine Behaviour and Physiology, 8, 135-148. http://dx.doi.org/10.1080/10236248109387010

Buresch, K. C., Ulmer, K. M., Akkaynak, D., Allen, J. J., Mäthger, L. M., Nakamura, M., \& Hanlon, R. T. (2015). Cuttlefish adjust body pattern intensity with respect to substrate intensity to aid camouflage, but do not camouflage in extremely low light. Journal of Experimental Marine Biology and Ecology, 462, 121-126. http://dx.doi.org/10.1016/i.jembe.2014.10.017

Byrne, R. A., Kuba, M. J., Meisel, D. V., \& Griebel, U. (2002). Lateral asymmetry of eye use in Octopus vulgaris. Animal Behaviour, 64, 461-468. http://dx.doi.org/10.1006/anbe.2002.3089

Byrne, R. A., Kuba, M. J., Meisel, D. V., Griebel, U., \& Mather, J. A. (2006). Does Octopus vulgaris have preferred arms? Journal of Comparative Psychology, 120, 198-204. http://dx.doi.org/10.1037/0735-7036.120.3.198 
Caldwell, R. L., Ross, R., Rodaniche, A., \& Huffard, C. L. (2015). Behavior and body patterns of the Larger Pacific Striped Octopus. PLOS ONE, 10, e0134152. http://dx.doi.org/10.1371/journal.pone.0134152

Calisti, M., Giorelli, M., Levy, G., Mazzolai, B., Hochner, B., Laschi, C., \& Dario, P. (2011). An octopus-bioinspired solution to movement and manipulation for soft robots. Bioinspiration \& Biomimetics, 6, 036002. http://dx.doi.org/10.1088/1748-3182/6/3/036002

Cheng, M. W., \& Caldwell, R. L. (2000). Sex identification and mating in the blue-ringed octopus, Hapalochlaena lunulata Animal Behaviour, 60, 27-33. http://dx.doi.org/10.1006/anbe.2000.1447

Chiao, C. C., Chubb, C., \& Hanlon, R. T. (2015). A review of visual perception mechanisms that regulate rapid adaptive camouflage in cuttlefish. Journal of Comparative Physiology A, Neuroethology, Sensory, Neural, and Behavioral Physiology, 201, 933-945. http://dx.doi.org/10.1007/s00359-015-0988-5

Chiao, C. C., Wickiser, J. K., Allen, J. J., Genter, B., \& Hanlon, R. T. (2011). Hyperspectral imaging of cuttlefish camouflage indicates good color match in the eyes of fish predators. PNAS Proceedings of the National Academy of Sciences of the United States of America, 108, 91489153. http://dx.doi.org/10.1073/pnas.1019090108

Cooper, K. M., Hanlon, R. T., \& Budelmann, B. U. (1990). Physiological color change in squid iridophores. Il. Ultrastructural mechanisms in Lolliguncula brevis. Cell and Tissue Research, 259, 1524. http://dx.doi.org/10.1007/BF00571425

Cosgrove, J. A. (2003). An in situ observation of webover hunting by Enteroctopus dofleini (Wülker, 1910). Canadian Field Naturalist, 117, 117-118.

Cosgrove, J. A., \& McDaniel, N. (2009). Super suckers: The giant Pacific octopus and other cephalopods of the Pacific coast. Madeira Park, Canada: Harbour Publishing.

Cowdry, E. V. (1911). The colour changes of Octopus vulgaris. University of Toronto Studies in Biology, 10, 1-53.

Crook, A. C., Baddeley, R., \& Osorio, D. (2002). Identifying the structure in cuttlefish visual signals. Philosophical Transactions of the Royal Society of London Series B, Biological Sciences, 357, 16171624. http://dx.doi.org/10.1098/rstb.2002.1070

Dew, B. (1959). Some observations on the development of two Australian octopuses. Proceedings of the Royal Zoological Society of New South Wales., 1957-1958, 44-52.

Drickamer, L. C., Vessey, S. H., \& Meikle, D. (1996). Animal behavior: Mechanisms, ecology, and evolution (4th ed.). Dubuque, IA: W. C. Brown.

Ferguson, G., Messenger, J., \& Budelmann, B. (1994). Gravity and light influence the countershading reflexes of the cuttlefish Sepia officinalis. The Journal of Experimental Biology, $191,247-256$. 
Flash, T., \& Hochner, B. (2005). Motor primitives in vertebrates and invertebrates. Current Opinion in Neurobiology, 15, 660-666. http://dx.doi.org/10.1016/j.conb.2005.10.011

Forsythe, J., \& Hanlon, R. (1988). Behavior, body patterning and reproductive biology of Octopus bimaculoides from California. Malacologia, 29, 41-55.

Froesch, D. (1973). Projection of chromatophore nerves onto the body surface of Octopus vulgaris. Marine Behaviour and Physiology, 19, 153-155.

Golani, I., \& Fentress, J. C. (1985). Early ontogeny of face grooming in mice. Developmental Psychobiology, 18, 529-544. http://dx.doi.org/10.1002/dev.420180609

Goldstein, E. B. (2002). Sensation and perception (6th ed.). Pacific Grove, CA: ThomsonWadsworth.

Grasso, F. (2014). The octopus with two brains: How are distributed and central representations integrated in the octopus? In A.-S. Darmaillaca, L. Dickel, \& J. A. Mather (Eds.), Cephalopod cognition (pp. 94-122). Cambridge, UK: Cambridge University Press. http://dx.doi.org/10.1017/CBO9781139058964.008

Greenberg, N. (1977). An ethogram of the blue spiny lizard, Sceloporus cyanogenys (Reptilia, Lacertilia, Iguanidae). Journal of Herpetology, 11, 177-195. http://dx.doi.org/10.2307/1563139

Gutfreund, Y., Flash, T., Fiorito, G., \& Hochner, B. (1998). Patterns of arm muscle activation involved in octopus reaching movements. The Journal of Neuroscience, 18, 5976-5987.

Gutfreund, Y., Flash, T., Yarom, Y., Fiorito, G., Segev, I., \& Hochner, B. (1996). Organization of octopus arm movements: A model system for studying the control of flexible arms. The Journal of Neuroscience, 16, 7297-7307.

Hanassy, S., Botvinnik, A., Flash, T., \& Hochner, B. (2015). Stereotypical reaching movements of the octopus involve both bend propagation and arm elongation. Bioinspiration \& Biomimetics, 10, 035001. http://dx.doi.org/10.1088/1748-3190/10/3/035001

Hanlon, R. T. (1983). Octopus joubini. In P. R. Boyle (Ed.), Cephalopod life cycles 1 (pp. 293-310). London, UK: Academic Press.

Hanlon, R. T. (1988). Behavioral and body patterning characters useful in taxonomy of field identification of cephalopods. Malacologia, 29, 247-264.

Hanlon, R. T., Conroy, L. A., \& Forsythe, J. W. (2008). Mimicry and foraging behavior of two tropical sand-flat octopus species off North Sulawesi, Indonesia. Biological Journal of the Linnean Society Linnean Society of London, 93, 23-38. http://dx.doi.org/10.1111/j.1095-8312.2007.00948.x

Hanlon, R. T., Forsythe, J. W., \& Joneschild, D. E. (1999). Crypsis, conspicuousness, mimicry and polyphenism as antipredator defences of foraging octopuses on Indo-Pacific coral reefs, with a method of quantifying crypsis from videotapes. Biological Journal of the Linnean Society Linnean Society of London, 66, 1-22. http://dx.doi.org/10.1111/j.1095-8312.1999.tb01914.x 
Hanlon, R. T., \& Hixon, R. F. (1980). Body patterning and field observations of Octopus burryi Voss, 1950. Bulletin of Marine Science, 30, 749-755.

Hanlon, R. T., \& Messenger, J. B. (1988). Adaptive coloration in young cuttlefish (Sepia officinalis L): The morphology and development of body patterns and their relation to behaviour. Philosophical Transactions of the Royal Society of London Series B, Biological Sciences, 320, 437487. http://dx.doi.org/10.1098/rstb.1988.0087

Hanlon, R. T., \& Messenger, J. B. (1996). Cephalopod behaviour. Cambridge, UK: Cambridge University Press.

Hanlon, R. T., Watson, A. C., \& Barbosa, A. (2010). A "mimic octopus" in the Atlantic: Flatfish mimicry and camouflage by Macrotritopus defilippi. The Biological Bulletin, 218, 15-24.

Hanlon, R. T., \& Wolterding, M. R. (1989). Behavior, body patterning, growth and life history of Octopus briareus cultured in the laboratory. American Malacological Bulletin, 7, 21-45.

Hochberg, F., Norman, M., \& Finn, J. (2006). Wunderpus photogenicus n. gen. and sp., a new octopus from the shallow waters of the Indo-Malayan Archipelago (Cephalopoda: Octopodidae). Molluscan Research, 26, 128-140.

Hochner, B. (2013). How nervous systems evolve in relation to their embodiment: What we can learn from octopuses and other molluscs. Brain, Behavior and Evolution, 82, 19-30. http://dx.doi.org/10.1159/000353419

Huffard, C. L. (2006). Locomotion by Abdopus aculeatus (Cephalopoda: Octopodidae): Walking the line between primary and secondary defenses. The Journal of Experimental Biology, 209, 3697-3707. http://dx.doi.org/10.1242/jeb.02435

Huffard, C. L. (2007a). Ethogram of Abdopus aculeatus (d'Orbigny, 1834) (Cephalopoda: Octopodidae): Can behavioral characters inform octopodid taxonomy and systematics? The Journal of Molluscan Studies, 73, 185-193. http://dx.doi.org/10.1093/mollus/eym015

Huffard, C. L. (2007b). Four new species of shallow water pygmy octopus (Mollusca: Cephalopoda) from the Kingdom of Tonga. Molluscan Research, 27, 147-170.

Huffard, C. L., Boneka, F., \& Full, R. J. (2005). Underwater bipedal locomotion by octopuses in disguise. Science, 307, 1927. http://dx.doi.org/10.1126/science.1109616

Huffard, C. L., Caldwell, R. L., DeLoach, N., Gentry, D. W., Humann, P., MacDonald, B., ... Wong, S. (2008). Individually unique body color patterns in octopus (Wunderpus photogenicus) allow for photoidentification. PLOS ONE, 3, e3732. http://dx.doi.org/10.1371/journal.pone.0003732

Huffard, C. L., Gentry, B. A., \& Gentry, D. W. (2009). Description of the paralarvae of Wunderpus photogenicus Hochberg, Norman \& Finn, 2006 (Cephalopoda: Octopodidae). The Raffles Bulletin of Zoology, 57, 109-112. 
Huffard, C. L., \& Godfrey-Smith, P. (2010). Field observations of mating in Octopus tetricus Gould, 1852 and Amphioctopus marginatus (Taki, 1964) (Cephalopoda: Octopodidae). Molluscan Research, 30, 81-86.

Huffard, C. L., Saarmann, N., Hamilton, H., \& Simison, W. B. (2010). The evolution of conspicuous facultative mimicry in octopuses: An example of secondary adaptation? Biological Journal of the Linnean Society Linnean Society of London, 101, 68-77. http://dx.doi.org/10.1111/j.1095$\underline{8312.2010 .01484 . x}$

Jensen, P. (1980). An ethogram of social interaction patterns in group-housed dry sows. Applied Animal Ethology, 6, 341-350. http://dx.doi.org/10.1016/0304-3762/80)90134-0

Josef, N., \& Shashar, N. (2014). Camouflage in benthic cephalopods: What does it teach us? In A.-S. Darmaillacq, L. Dickel, \& J. A. Mather (Eds.), Cephalopod cognition (pp. 177-196). Cambridge, UK: Cambridge University Press. http://dx.doi.org/10.1017/CBO9781139058964.012

Kier, W. M., \& Smith, A. M. (1990). The morphology and mechanics of octopus suckers. The Biological Bulletin, 178, 126-136. http://dx.doi.org/10.2307/1541971

Kier, W. M., \& Smith, A. M. (2002). The structure and adhesive mechanism of octopus suckers. Integrative and Comparative Biology, 42, 1146-1 153. http://dx.doi.org/10.1093/icb/42.6.1146

Kier, W. M., \& Smith, K. K. (1985). Tongues, tentacles and trunks: The biomechanics of movement in muscular-hydrostats. Zoological Journal of the Linnean Society, 83, 307-324. http://dx.doi.org/10.1111/j.1096-3642.1985.tb01178.x

Kier, W. M., \& Stella, M. P. (2007). The arrangement and function of octopus arm musculature and connective tissue. Journal of Morphology, 268, 831-843. http://dx.doi.org/10.1002/jmor.10548

Kier, W. M., \& Thompson, J. T. (2003). Muscle arrangement, function and specialization in recent coleoids. Berlin Paläeobiological Abhandlungen, 3, 141-162.

Laan, A., Gutnick, T., Kuba, M. J., \& Laurent, G. (2014). Behavioral analysis of cuttlefish traveling waves and its implications for neural control. Current Biology, 24, 1737-1742. http://dx.doi.org/10.1016/j.cub.2014.06.027

Leite, T. S., Haimovici, M., Molina, W., \& Warnke, K. (2008). Morphological and genetic description of Octopus insularis, a new cryptic species in the Octopus vulgaris complex (Cephalopoda: Octopodidae) from the tropical southwestern Atlantic. The Journal of Molluscan Studies, 74, 6374. http://dx.doi.org/10.1093/mollus/eym050

Leite, T. S., \& Mather, J. A. (2008). A new approach to octopuses' body pattern analysis: A framework for taxonomy and behavioral studies. American Malacological Bulletin, 24, 31-41. http://dx.doi.org/10.4003/0740-2783-24.1.31

Levy, G., Flash, T., \& Hochner, B. (2015). Arm coordination in octopus crawling involves unique motor control strategies. Current Biology, 25, 1195-1200. http://dx.doi.org/10.1016/i.cub.2015.02.064 
Mangold, K., \& Von Boletzky, S. (1973). New data on reproductive biology and growth of Octopus vulgaris. Marine Biology, 19, 7-12. http://dx.doi.org/10.1007/BF00355414

Mann, T. (1984). Spermatophores: Development, structure, biochemical attributes and role in the transfer of spermatozoa. Berlin, Germany: Springer-Verlag. http://dx.doi.org/10.1007/978-3-64282308-4

Mather, J. A. (1978). Mating behavior of Octopus joubini Robson. The Veliger, 21, 265-267.

Mather, J. A. (1984). Development of behaviour in Octopus joubini Robson, 1929. Vie et Milieu, 34, 17-20.

Mather, J. A. (1986). Sand digging in Sepia officinalis: Assessment of a cephalopod mollusc's "fixed" behavior pattern. Journal of Comparative Psychology, 100, 315-320. http://dx.doi.org/10.1037/0735-7036.100.3.315

Mather, J. A. (1991). Foraging, feeding and prey remains in middens of juvenile Octopus vulgaris (Mollusca: Cephalopoda). Journal of Zoology, 224, 27-39. http://dx.doi.org/10.1111/j.14697998.1991.tb04786.x

Mather, J. A. (1994). "Home" choice and modification by juvenile Octopus vulgaris (Mollusca: Cephalopoda): Specialized intelligence and tool use? Journal of Zoology, 233, 359-368. http://dx.doi.org/10.1111/j.1469-7998.1994.tb05270.x

Mather, J. A. (1998). How do octopuses use their arms? Journal of Comparative Psychology, 112, $306-316$. http://dx.doi.org/10.1037/0735-7036.112.3.306

Mather, J. A. (2004). Cephalopod skin displays: From concealment to communication. In K. Oller \& U. Griebel (Eds.), Evolution of communication systems (pp. 193-213). Cambridge, MA: MIT Press.

Mather, J. A., Griebel, U., \& Byrne, R. (2010). Squid dances: An ethogram of body postures and actions of Sepioteuthis sepioidea squid with a muscular hydrostat system. Marine and Freshwater Behaviour and Physiology, 43, 45-61. http://dx.doi.org/10.1080/10236241003660771

Mather, J. A., \& Mather, D. L. (1994). Skin colours and patterns of juvenile Octopus vulgaris (Mollusca, Cephalopoda) in Bermuda. Vie et Milieu, 44, 267-272.

Mather, J. A., \& Mather, D. L. (2004). Apparent movement in a visual display: The 'Passing Cloud' of Octopus cyanea (Mollusca: Cephalopoda). Journal of Zoology, 263, 89-94. http://dx.doi.org/10.1017/S0952836904004911

Mäthger, L. M., Bell, G. R. R., Kuzirian, A. M., Allen, J. J., \& Hanlon, R. T. (2012). How does the blueringed octopus (Hapalochlaena lunulata) flash its blue rings? The Journal of Experimental Biology, 215, 3752-3757. http://dx.doi.org/10.1242/jeb.076869

Mäthger, L. M., Denton, E. J., Marshall, N. J., \& Hanlon, R. T. (2009). Mechanisms and behavioural functions of structural coloration in cephalopods. Journal of the Royal Society, Interface, 6, S149S163. http://dx.doi.org/10.1098/rsif.2008.0366.focus 
Meisel, D. V., Byrne, R. A., Kuba, M., \& Mather, J. A. (2011). Behavioural sleep in Octopus vulgaris. Vie et Milieu, 61, 185-190.

Meisel, D. V., Byrne, R. A., Kuba, M., Mather, J., Ploberger, W., \& Reschenhofer, E. (2006). Contrasting activity patterns of two related octopus species, Octopus macropus and Octopus vulgaris. Journal of Comparative Psychology, 120, 191-197. http://dx.doi.org/10.1037/0735$\underline{7036.120 .3 .191}$

Messenger, J. B. (1967). The peduncle lobe: A visuo-motor centre in Octopus. Proceedings of the Royal Society of London, Series B: Biological Sciences, 167, 225-251. http://dx.doi.org/10.1098/rspb.1967.0025

Messenger, J. B. (2001). Cephalopod chromatophores: Neurobiology and natural history. Biological Reviews of the Cambridge Philosophical Society, 76, 473-528. http://dx.doi.org/10.1017/S1464793101005772

Miske, V., \& Kirchhauser, J. (2006). First record of brooding and early life cycle stages in Wunderpus photogenicus Hochberg, Norman \& Finn, 2006 (Cephalopoda: Octopodidae). Molluscan Research, 26, 169-171.

Moguel, C., Mascaró, M., Avila-Poveda, O. H., Caamal-Monsreal, C., Sanchez, A., Pascual, C., \& Rosas, C. (2010). Morphological, physiological and behavioral changes during post-hatching development of Octopus maya (Mollusca: Cephalopoda) with special focus on the digestive system. Aquatic Biology, 9, 35-48. http://dx.doi.org/10.3354/ab00234

Mohanty, S., Ojanguren, A. F., \& Fuiman, L. A. (2014). Aggressive male mating behavior depends on female maturity in Octopus bimaculoides. Marine Biology, 161, 1521-1530. http://dx.doi.org/10.1007/s00227-014-2437-3

Moody, M. F., \& Parriss, J. R. (1960). Discrimination of polarized light by octopus. Nature, 186, 839840. http://dx.doi.org/10.1038/186839a0

Moynihan, M. (1975). Conservatism of displays and comparable stereotyped patterns among cephalopods. In G. Baerends, C. Beer, \& A. Manning (Eds.), Function and evolution of behavior: Essays in honour of Professor Niko Tinbergen, F. R. S (pp. 276-291). Oxford, UK: Oxford University Press.

Nesher, N., Levy, G., Grasso, F. W., \& Hochner, B. (2014). Self-recognition mechanism between skin and suckers prevents octopus arms from interfering with each other. Current Biology, 24, 1271-1275. http://dx.doi.org/10.1016/j.cub.2014.04.024

Nixon, M. (1980). The salivary papilla of Octopus as an accessory radula for drilling shells. Journal of Zoology, 190, 53-57. http://dx.doi.org/10.1111/j.1469-7998.1980.tb01422.x

Nixon, M., Maconnachie, E., \& Howell, P. G. T. (1980). The effects on shells of drilling by Octopus. Journal of Zoology, 191, 75-88. http://dx.doi.org/10.1111/j.1469-7998.1980.tb01450.x 
Norman, M. D. (1992a). Four new octopus species of the Octopus macropus group (Cephalopoda: Octopodidae) from the Great Barrier Reef, Australia. Memoirs of the Museum of Victoria, 53, 267-308.

Norman, M. D. (1992b). Ocellate octopuses (Cephalopoda: Octopodidae) of the Great Barrier Reef, Australia: Description of two new species and redescription of Octopus polyzenia Gray, 1849. Memoirs of the Museum of Victoria, 53, 309-344.

Norman, M. D., Finn, J. K., \& Hochberg, F. G. (2014). Family Octopodidae. In P. Jereb, C. F. E. Roper, M. D. Norman and J. K. Finn (Eds.), Cephalopods of the world: An annotated and illustrated catalogue of cephalopod species known to date. Vol. 3. Octopods and Vampire Squids (pp. 36-215). FAO Species Catalogue for Fishery Purposes. No. 4, Vol. 3. Rome, Italy: Food and Agriculture Organization of the United Nations.

Norman, M., \& Hochberg, F. (2005). The "mimic Octopus" (Thaumoctopus mimicus n. gen. et sp.), a new octopus from the tropical Indo-West Pacific (Cephalopoda: Octopodidae). Molluscan Research, 25, 57-70.

O'Dor, R. K., \& Webber, D. M. (1986). The constraints on cephalopods: Why squid aren't fish. Canadian Journal of Zoology, 64, 1591-1605. http://dx.doi.org/10.1139/z86-241

Okamoto, K., Mori, A., \& Ikeda, Y. (2015). Effects of visual cues of a moving model on body patterns in cuttlefish Sepia pharaonis. Zoological Science, 32, 336-344. http://dx.doi.org/10.2108/zs1 40288

Ortiz, N., Ré, M. E., \& Márquez, F. (2006). First description of eggs, hatchlings and hatchling behavior of Enteroctopus megalocyathus (Cephalopoda: Octopodidae). Journal of Plankton Research, 28, 881-890. http://dx.doi.org/10.1093/plankt/fbl023

Packard, A. (1961). Sucker display of Octopus. Nature, 190, 736-737. http://dx.doi.org/10.1038/190736a0

Packard, A. (1992). Nerve-induced and myogenically propagated relaxations of skin muscle (Octopus vulgaris). The Journal of Physiology, 452, 130P.

Packard, A. (1995). Organization of cephalopod chromatophore systems: A neuromuscular image-generator. In N. J. Abbott, R. Williamson, \& L. Maddock (Eds.), Cephalopod Neurobiology (pp. 331-368). Oxford, UK: Oxford University Press. http://dx.doi.org/10.1093/acprof:oso/9780198547907.003.0226

Packard, A., \& Hochberg, F. G. (1977). Skin patterning in Octopus and other genera. In M. Nixon \& J. B. Messenger (Eds.), The biology of cephalopods (pp. 191-231). London, UK: Academic Press.

Packard, A., \& Sanders, G. (1971). Body patterns of Octopus vulgaris and maturation of the response to disturbance. Animal Behaviour, 19, 780-790. http://dx.doi.org/10.1016/S0003$\underline{3472(71) 80181-1}$ 
Pearson, K. G. (1993). Common principles of motor control in vertebrates and invertebrates. Annual Review of Neuroscience, 16, 265-297. http://dx.doi.org/10.1146/annurev.ne.16.030193.001405

Pellis, S. M. (2011). Head and foot coordination in head scratching and food manipulation by purple swamp hens (Porphyrio porphyrio): Rules for minimizing the computational costs of combining movements from multiple parts of the body. International Journal of Comparative Psychology, 24, 255-271.

Pellis, S. M., Gray, D., \& Cade, W. H. (2009). The judder of the cricket: The variance underlying the invariance in behavior. International Journal of Comparative Psychology, 22, 188-205.

Pellis, S. M., Pellis, V. C., \& Iwaniuk, A. N. (2014). Pattern in behavior: The characterization, origins, and evolution of behavior patterns. Advances in the Study of Behavior, 46, 127-189. http://dx.doi.org/10.1016/B978-0-12-800286-5.00004-3

Petrù, M., Spinka, M., Charvátová, V., \& Lhota, S. (2009). Revisiting play elements and selfhandicapping in play: A comparative ethogram of five Old World monkey species. Journal of Comparative Psychology, 123, 250-263. http://dx.doi.org/10.1037/a0016217

Polese, G., Bertapelle, C., \& Di Cosmo, A. (2015). Role of olfaction in Octopus vulgaris reproduction. General and Comparative Endocrinology, 210, 55-62. http://dx.doi.org/10.1016/j.ygcen.2014.10.006

Promboon, P., Nabhitabhata, J., \& Duengdee, T. (2011). Life cycle of the marbled octopus, Amphioctopus aegina (Gray) (Cephalopoda: Octopodidae) reared in the laboratory. Scientia Marina, 75, 811-821. http://dx.doi.org/10.3989/scimar.2011.75n4811

Richter, J. N., Hochner, B., \& Kuba, M. J. (2015). Octopus arm movements under constrained conditions: Adaptation, modification and plasticity of motor primitives. The Journal of Experimental Biology, 218, 1069-1076. http://dx.doi.org/10.1242/jeb.115915

Robson, G. C. (1929). A monograph of the recent cephalopoda. Part I. Octopodinae. London, UK: British Museum.

Rodaniche, A. F. (1984). Iteroparity in the lesser Pacific striped octopus Octopus chierchiae (Jatta, 1889). Bulletin of Marine Science, 35, 99-104.

Rodaniche, A. F. (1991). Notes on the behavior of the larger Pacific striped octopus, an undescribed species of the genus Octopus. [Abstract]. Bulletin of Marine Science Abstracts, 49, 667.

Roper, C. F. E., \& Hochberg, F. G. (1988). Behavior and systematics of cephalopods from Lizard Island, Australia, based on color and body patterns. Malacologia, 29, 153-193.

Rowell, C. H. F. (1963). Excitatory and inhibitory pathways in the arm of Octopus. The Journal of Experimental Biology, 40, 257-270. 
Rowell, C. H. F. (1966). Activity of interneurones in the arm of Octopus in response to tactile stimulation. The Journal of Experimental Biology, 44, 589-605.

Ruby, D., \& Niblick, H. (1994). A behavioral inventory of the desert tortoise: Development of an ethogram. Herpetological Monograph, 8, 88-102. http://dx.doi.org/10.2307/1467073

Ruiz, J. F., Sepulveda, R. D., \& Ibanez, C. M. (2012). Behavior of Robsonella fontaniana in response to a potential predator. Latin American Journal of Aquatic Research, 40, 253-258. http://dx.doi.org/10.3856/vol40-issue2-fulltext-1

Saraiva, R. de S.-N. (2006). Classic ethology reappraised. Behavior and Philosophy, 34, 89-107.

Sfakiotakis, M., Lane, D. M., \& Davies, J. B. C. (1999). Review of fish swimming modes for aquatic locomotion. IEEE Journal of Oceanic Engineering, 24, 237-252. http://dx.doi.org/10.1 109/48.757275

Smith, K. K., \& Kier, W. M. (1989). Trunks, tongues and tentacles: Moving with skeletons of muscle. American Scientist, 77, 28-35.

Solem, A. (1974). The shell makers: Introducing mollusks. New York, NY: Wiley.

Sreeja, V., \& Bijukumar, A. (2013). Ethological studies of the veined cctopus Amphioctopus marginatus (Taki) (Cephalopoda: Octopodidae) in captivity, Kerala, India. Journal of Threatened Taxa, 5, 4492-4497. http://dx.doi.org/10.11609/JoTT.03256.4492-7

Steer, M. A., \& Semmens, J. M. (2003). Pulling or drilling: Does size or species matter? An experimental study of prey handling in Octopus dierythraeus (Norman, 1992). Journal of Experimental Marine Biology and Ecology, 290, 165-178. http://dx.doi.org/10.1016/S0022$\underline{0981(03) 00076-5}$

Sumbre, G., Gutfreund, Y., Fiorito, G., Flash, T., \& Hochner, B. (2001). Control of octopus arm extension by a peripheral motor program. Science, 293, 1845-1848. http://dx.doi.org/10.1126/science.1060976

Thompson, J. T., \& Voight, J. R. (2003). Erectile tissue in an invertebrate animal: The Octopus copulatory organ. Journal of Zoology, 261, 101-108. http://dx.doi.org/10.1017/S0952836903003996

Toussaint, R. K., Scheel, D., Sage, G. K., \& Talbot, S. L. (2012). Nuclear and mitochondrial markers reveal evidence for genetically segregated cryptic speciation in giant Pacific octopuses from Prince William Sound, AK. Conservation Genetics, 13, 1483-1497. http://dx.doi.org/10.1007/s10592-012-0392-4

Tramacere, F., Appel, E., Mazzolai, B., \& Gorb, S. N. (2014). Hairy suckers: The surface microstructure and its possible functional significance in the Octopus vulgaris sucker. Beilstein Journal of Nanotechnology, 5, 561-565. http://dx.doi.org/10.3762/bjnano.5.66 
Tramacere, F., Beccai, L., Kuba, M., Gozzi, A., Bifone, A., \& Mazzolai, B. (2013). The morphology and adhesion mechanism of Octopus vulgaris suckers. PLOS ONE, 8, e65074. http://dx.doi.org/10.1371/journal.pone.0065074

Tranter, D. J., \& Augustine, O. (1973). Observations on the life history of the blue-ringed octopus. Hapalochlaena maculosa, 18, 115-128.

Uyeno, T. A., \& Kier, W. M. (2007). Electromyography of the buccal musculature of octopus (Octopus bimaculoides): A test of the function of the muscle articulation in support and movement. The Journal of Experimental Biology, 210, 118-128. http://dx.doi.org/10.1242/jeb.02600

Vevers, H. G. (1961). Observations on the laying and hatching of octopus eggs in the Society's aquarium. Proceedings of the Zoological Society of London, 137, 311-315. http://dx.doi.org/10.1111/i.1469-7998.1961.tb05904.x

Villanueva, R. (1995). Experimental rearing and growth of planktonic Octopus vulgaris from hatching to settlement. Canadian Journal of Fisheries and Aquatic Sciences, 52, 2639-2650. http://dx.doi.org/10.1139/f95-853

Villanueva, R., Nozais, C., \& Boletzky, S. V. (1997). Swimming behavior and food searching in planktonic Octopus vulgaris Cuvier from hatching to settlement. Journal of Experimental Marine Biology and Ecology, 208, 169-184. http://dx.doi.org/10.1016/S0022-0981(96)02670-6

Voight, J. R. (1991a). Enlarged suckers as an indicator of male maturity in Octopus. Bulletin of Marine Science, 49, 98-106.

Voight, J. R. (1991b). Ligula length and courtship in Octopus digueti: A potential mechanism of mate choice. Evolution; International Journal of Organic Evolution, 45, 1726-1730. http://dx.doi.org/10.2307/2409795

Voight, J. R. (2005). Hydrothermal vent octopuses of Vulcanoctopus hydrothermalis, feed on bathypelagic amphipods of Halice hesmonectes. Journal of the Marine Biological Association of the United Kingdom, 85, 985-988. http://dx.doi.org/10.1017/S0025315405011999

Voight, J. R. (2008). Observations of deep-sea octopodid behavior from undersea vehicles. American Malacological Bulletin, 24, 43-50. http://dx.doi.org/10.4003/0740-2783-24.1.43

Voss, G. L., \& Phillips, C. (1957). A first record of Octopus macropus Risso from the United States with notes on its behavior, color, feeding and gonads. Quarterly Journal of the Florida Academy of Science, 20, 223-232.

Warren, L. R., Scheier, M. F., \& Riley, D. A. (1974). Colour changes of Octopus rubescens during attacks on unconditioned and conditioned stimuli. Animal Behaviour, 22, 211-219. http://dx.doi.org/10.1016/s0003-3472(74)80071-0

Wells, M. J. (1978). Octopus: Physiology and behavior of an advanced invertebrate. London, UK: Chapman and Hall. http://dx.doi.org/10.1007/978-94-017-2468-5 
Wells, M. J., \& O'Dor, R. K. (1991). Jet propulsion and the evolution of the cephalopods. Bulletin of Marine Science, 49, 419-432.

Wells, M. J., \& Smith, P. J. S. (1985). The ventilation cycle in Octopus. The Journal of Experimental Biology, 116, 375-383.

Wells, M. J., \& Wells, J. (1970). Observations on the feeding, growth rate and habits of newly settled Octopus cyanea. Journal of Zoology, 161, 65-74. http://dx.doi.org/10.1111//.14697998.1970.tb02170.x

Wells, M. J., \& Wells, J. (1972). Sexual displays and mating of Octopus vulgaris Cuvier and $O$. cyanea Gray and attempts to alter performance by manipulating the glandular condition of the animals. Animal Behaviour, 20, 293-308. http://dx.doi.org/10.1016/S0003-3472(72)80051-4

Wodinsky, J. (1973). Ventilation rate and copulation in Octopus vulgaris. Marine Biology, 20, 154164. http://dx.doi.org/10.1007/BF00351454

Wodinsky, J. (2008). Reversal and transfer of spermatophores by Octopus vulgaris and 0 . hummelincki. Marine Biology, 155, 91-103. http://dx.doi.org/10.1007/s00227-008-1010-3

Wood, J., Maynard, A. E., Lawlor, A. G., Sawyer, E. K., Simmons, D. M., Pennoyer, K. E., \& Derby, C. E. (2010). Caribbean reef squid, Sepioteuthis sepioidea, use ink as a defence against predatory French grunt, Haemulon flavolineatum. Journal of Experimental Marine Biology and Ecology, 389, 2027.

Yarnall, J. L. (1969). Aspects of the behavior of Octopus cyanea Gray. Animal Behaviour, 17, 747-754. http://dx.doi.org/10.1016/S0003-3472/69)80022-9

Yekutieli, Y., Flash, T., \& Hochner, B. (2009). Biomechanics: Hydroskeletal. Encyclopedia of Neuroscience, 2, 189-200.

Young, J. Z. (1962). Courtship and mating by a coral reef octopus (O. horridus). Proceedings of the Zoological Society, 138, 157-162. http://dx.doi.org/10.1111/j.1469-7998.1962.tb05693.x

Zelman, I., Titon, M., Yekutieli, Y., Hanassy, S., Hochner, B., \& Flash, T. (2013). Kinematic decomposition and classification of octopus arm movements. Frontiers in Computational Neuroscience, 7, 60. http://dx.doi.org/10.3389/fncom.2013.00060

Zullo, L., Sumbre, G., Agnisola, C., Flash, T., \& Hochner, B. (2009). Nonsomatotopic organization of the higher motor centers in Octopus. Current Biology, 19, 1632-1636. http://dx.doi.org/10.1016/i.cub.2009.07.067 